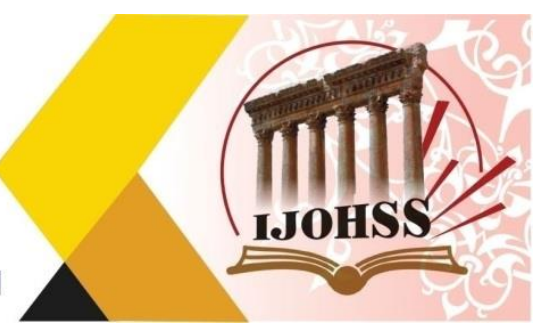

\title{
قياس الذات الرقمية لدى طلبة الجامعة
}

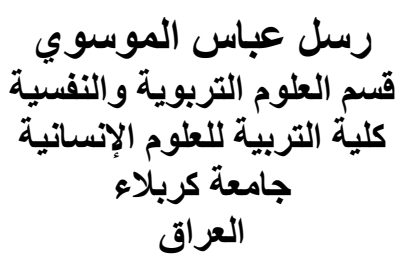

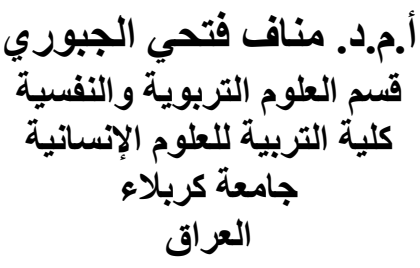

أ.م.د. مناف فتحي الجبوري

قسم العلوم التربوية والنفسية التية

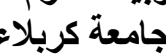

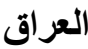

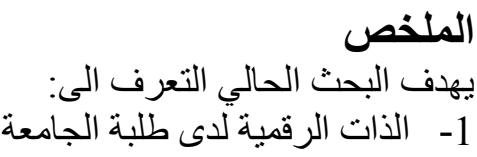

2- الفروق ذات الدلالة الإحصائية في الذات الرقمية على وفق متغيري النوع (ذكور - اناث) و التخصص

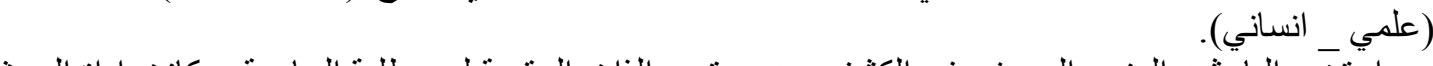
استخدم الباحثين المنهج الوصفي في الكثف عن مستوى الذات الرقمية لدى طلبة الجامعة، وكانت اداة البحث

- مقياس الذات الرقمية: من خلال الاطلاع على دراسات سابقة التي تنتاولت متغير الذات الرقمية، إذ تبنت

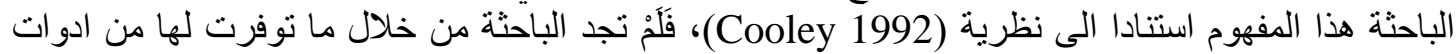

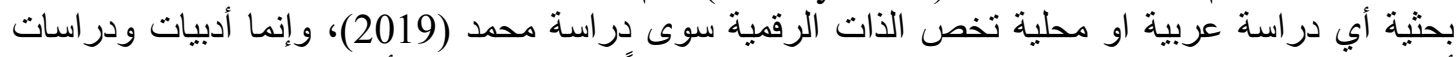

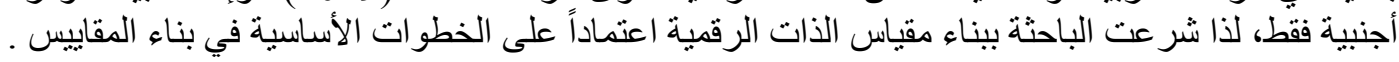

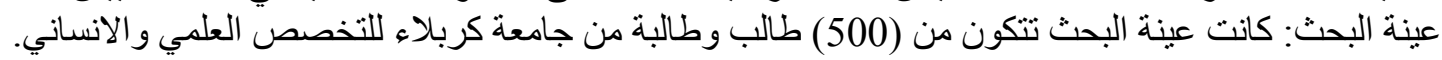
نتائج البحث: البش: بعد جمع البيانات ومعالجتها إحصائيا، توصل البحث الى النتائج الآتية: 1. 1 إن شريحة طلبة الجامعة لديهم ذات رقية التية.

2.

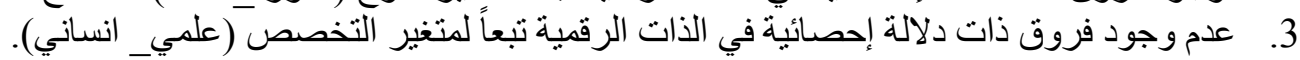

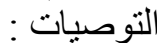
بناء على النتائج التي توصل إليها البحث الحالي توصي الباحثة بإقامة بر امج تربوية والارشادية التي ترفع من

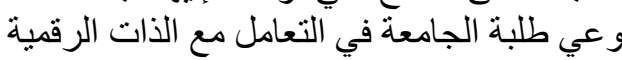

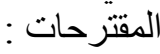
في ضوء نتائج البحث تقترح الباحثة إجر اء در اسة ممائلة لثر ائح أخرى كطلبة المدارس. الكلمات المفتاحية: الذات الرقمية، طلبة الجامعة. 


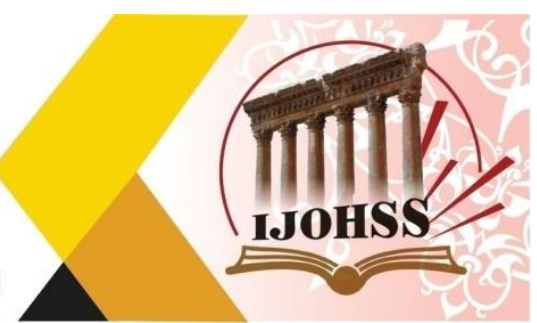

\title{
Measuring the Digital Self among University Students
}

\author{
Assist. Prof. Dr. Manaf Fathi Al-Jubouri \\ Department of Educational and \\ Psychological Sciences \\ College of Education for the Humanities \\ Karbala University - Iraq
}

\author{
Russell Abbas Al-Moussawi \\ Department of Educational and \\ Psychological Sciences \\ College of Education for the Humanities \\ Karbala University - Iraq
}

\begin{abstract}
The current research aims to identify:

1- The digital self among university students.

2- The statistically significant differences in the digital self-according to the gender variable (male - female) and specialization variable (scientific - human).

The researcher used the descriptive approach to reveal the level of the digital self and the among university students. The search tool was:

- Digital Self Scale: By looking at previous studies that dealt with the digital selfvariable, as the researcher adopted this concept based on the theory (Cooley 1992), so the researcher did not find, through the research tools available to them, any Arab or local study regarding the digital self. Except for the study of Muhammad (2019), but only foreign literature and studies, so the researcher set out to build a digital self-scale based on the basic steps in building scales.

Research sample: The research sample consisted of (500) male and female students from Karbala University for the scientific and humanitarian specialization.

Research results: After data collection and statistical processing, the research reached the following Results :

.1The segment of university students is digital.

.2 There are statistically significant differences in the digital self-according to the gender variable (males - females), in favor of males.

.3 There are no statistically significant differences in the digital self-according to the specialization variable (scientific - human).

Recommendations: Based on the findings of the current research, the researcher recommend the establishment of educational and extension programs that raise the awareness of university students in dealing with the digital self.

Suggestions: The researcher suggested conducting a similar study for other segments, such as school students.
\end{abstract}

Keywords: The digital self, university students. 


\section{الفصل الاول}

مشكلة البحث

يعيش العالم اليوم تقدما كبير ا اذ احتلت التكنلوجيا الرقمية الصدارة و هيمنت على التى اغلب جو انب الحياة فاصبح

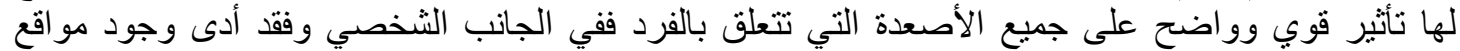

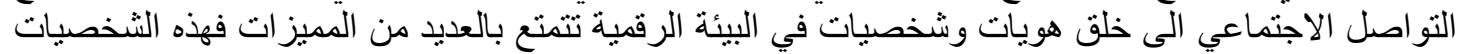

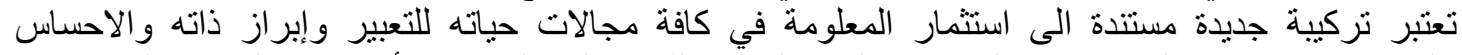

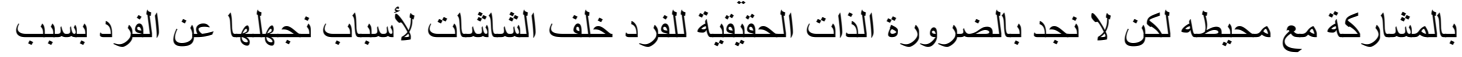

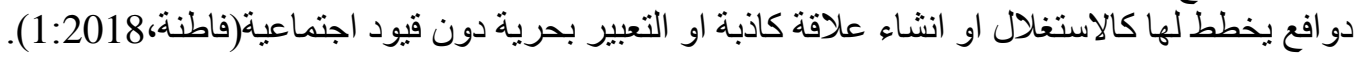

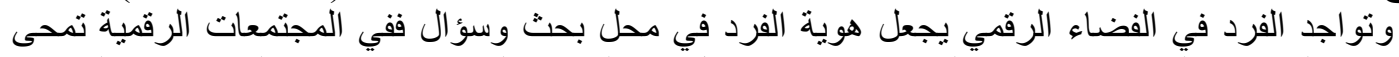

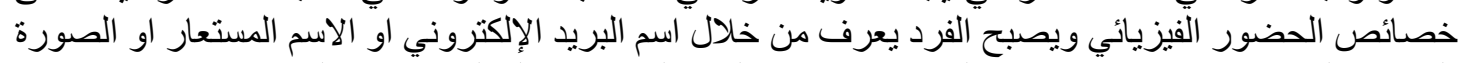

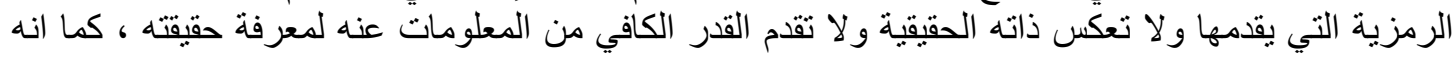

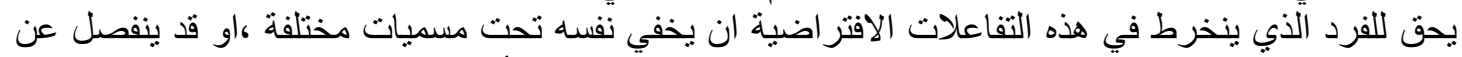

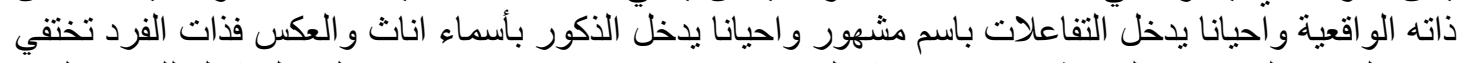

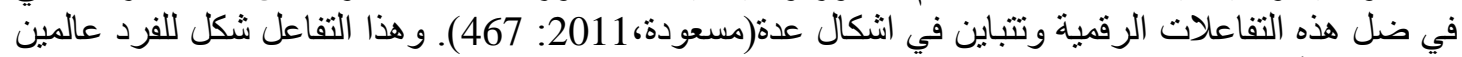

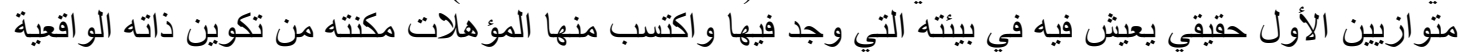

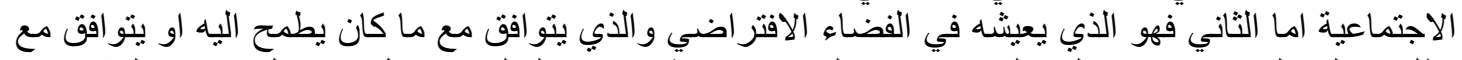

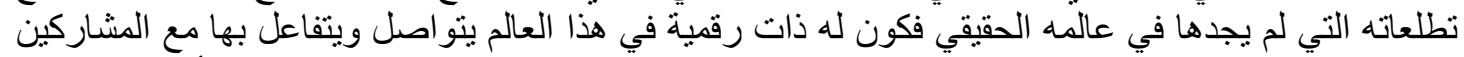

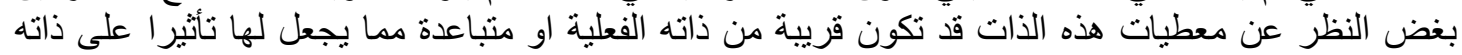

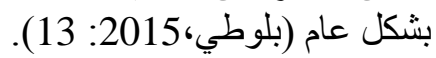

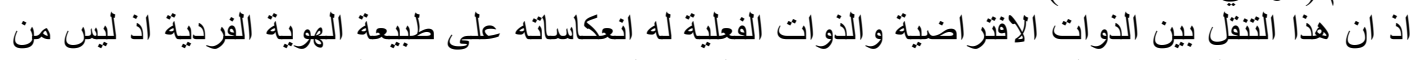

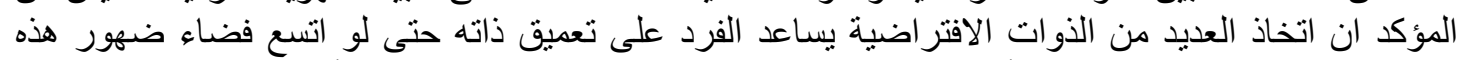

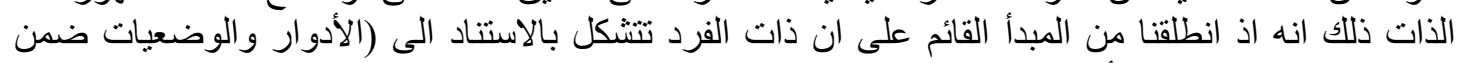

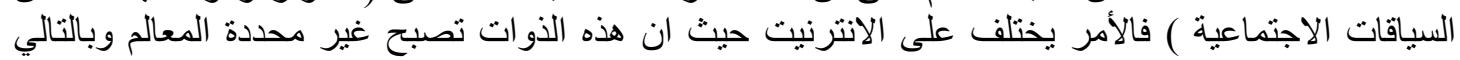

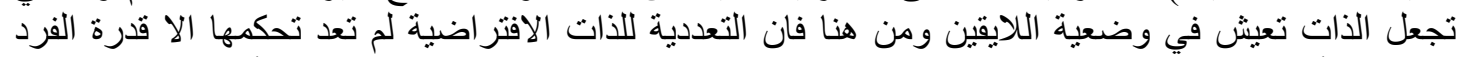

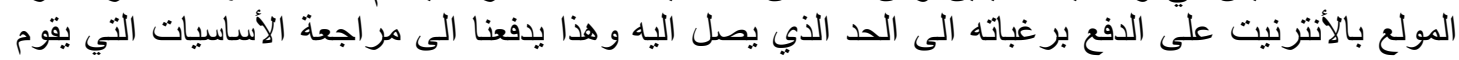

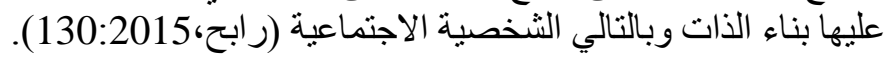

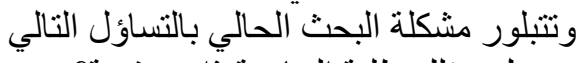

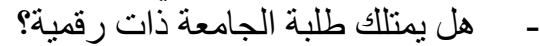

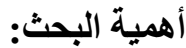

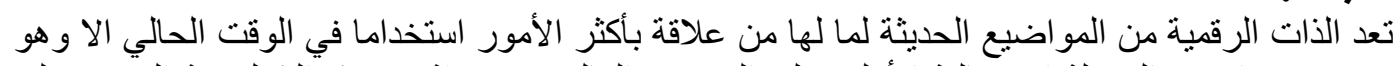

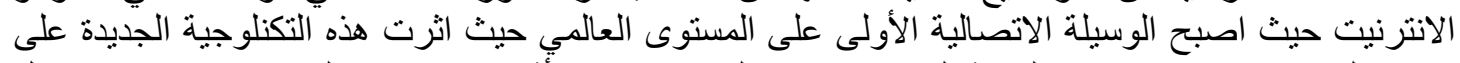

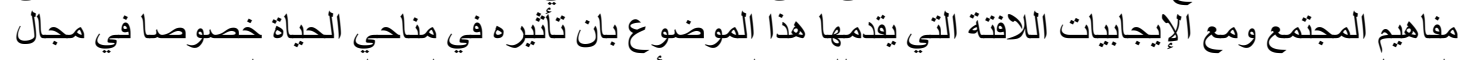

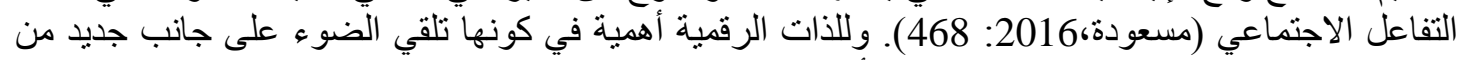

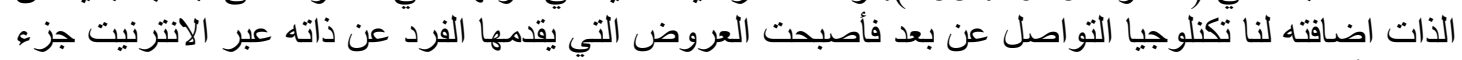

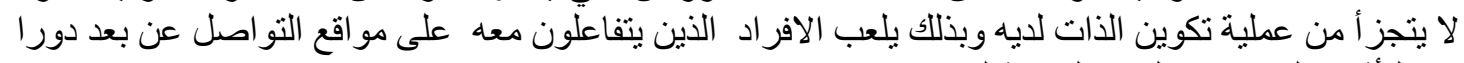

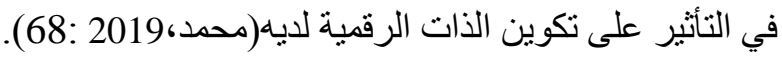

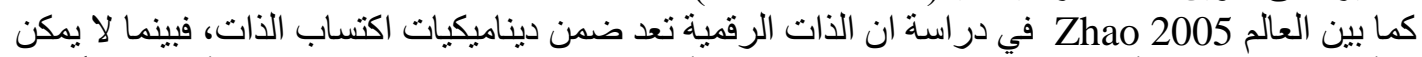

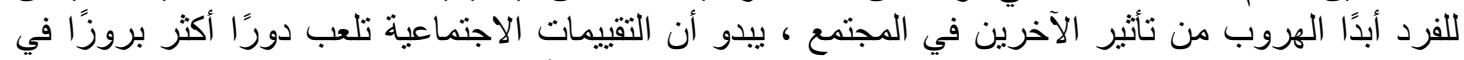

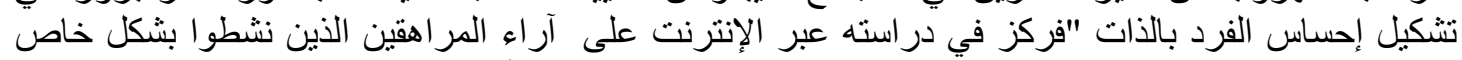

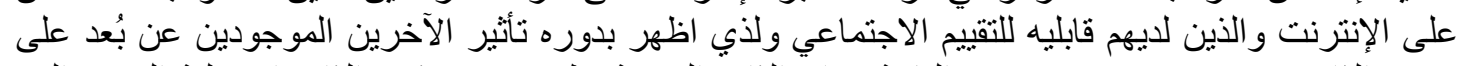

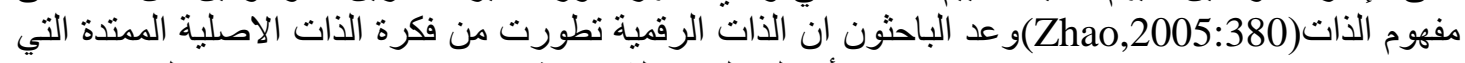

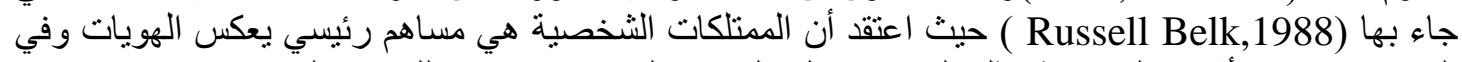

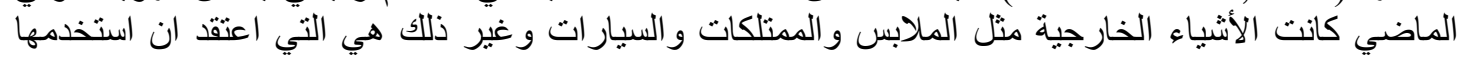




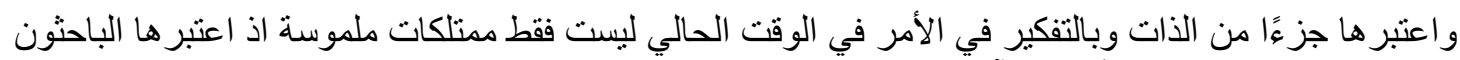

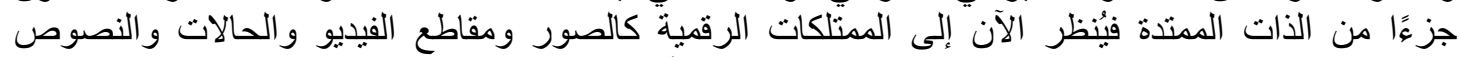

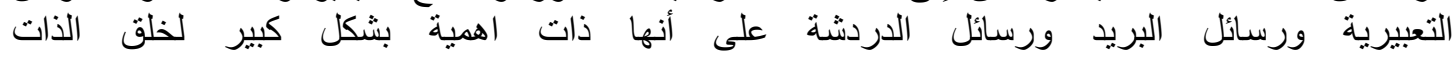

الرقمية(البحئة:139:Belk.1988).

$$
\text { 1 الهدف البحث البحث: }
$$

2- الفروق ذات الدلالة الإحصائية في الذات الرقمية على وفق متغير (الجنس و التخصصة)

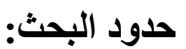

يقتصر البحث على عينة من طلبة جامعة كربلاء من كلا الجنسين ومن ذوي التخصصات الإنسانية و العلمية. تحديد مصطلحات البحث:

اولا الذات الرقمية: عرفهات كل من من

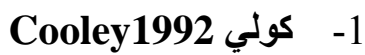

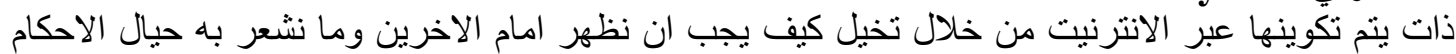

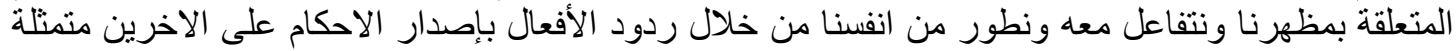

باستجابات لفظية و غير لفظية (Cooley,1992:6)

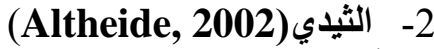

بأنها ذات يتم تصميمها على الانترنت تحت تأثثير الجمهور الالكتروني (Altheide, 2002:42).

ثانيا طلبة الجامعة

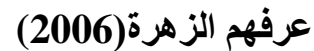

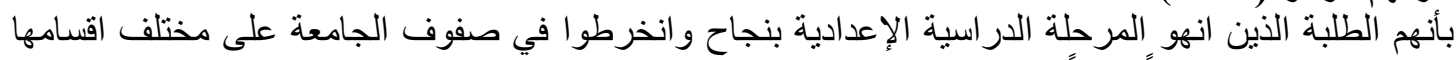

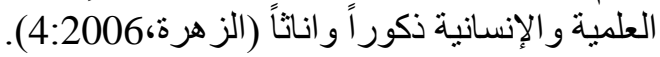

\section{اطار نظري ودراسات سابقة الثاني}

أولا الاطار النظري /نبذة تاريخية عن الذات الرقمية:

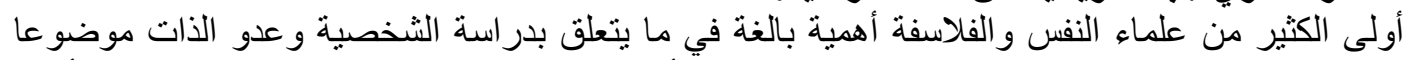

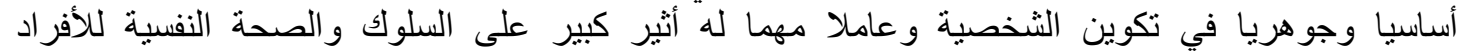

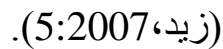
فكانت من أولى المو اضيع التي كتب عنها وليم جيمس William) James1890 ) اذ تناول الذات الذات ضمن

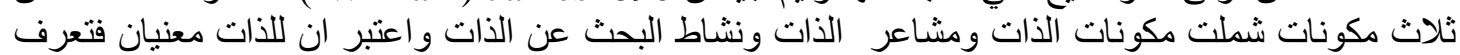

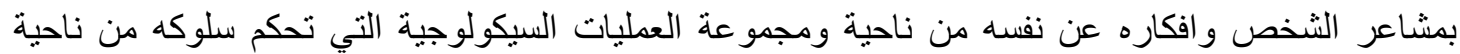

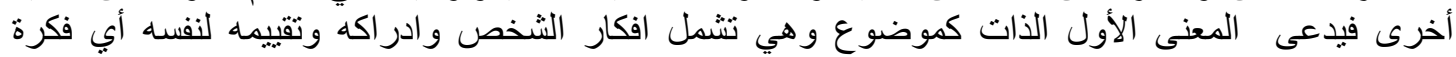

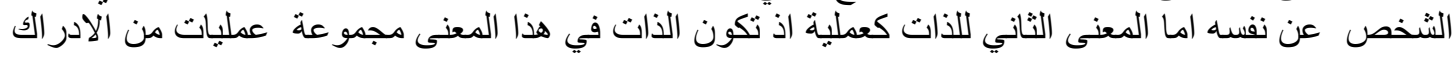

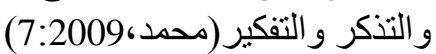

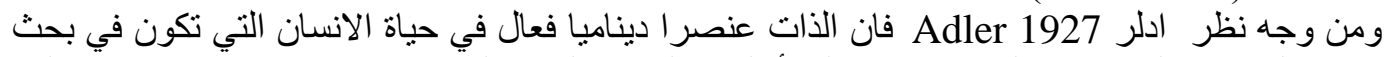

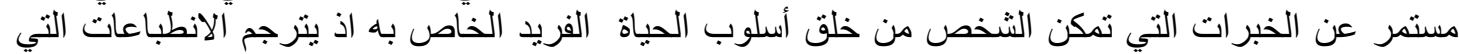

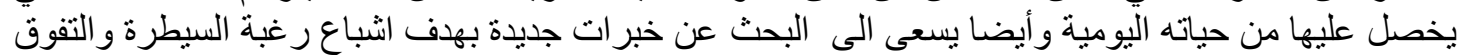

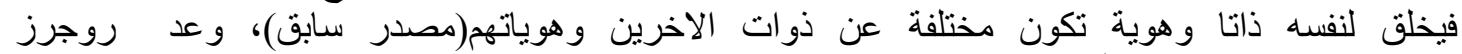

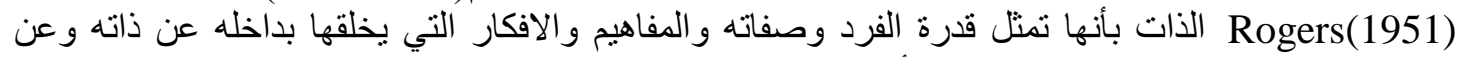

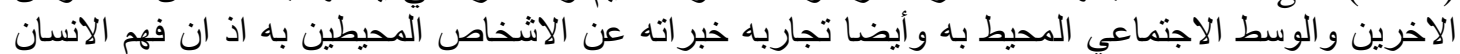




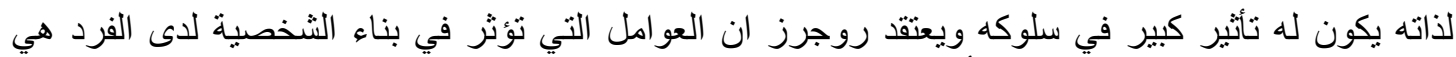

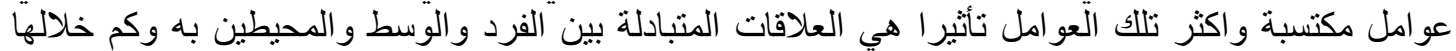

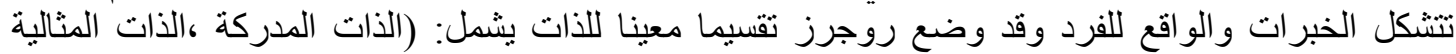

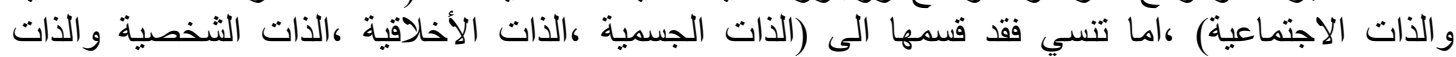

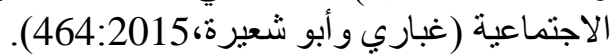

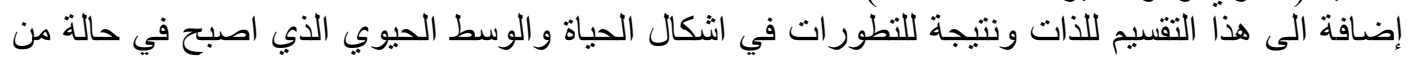

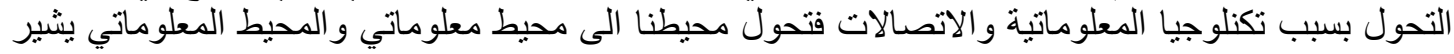

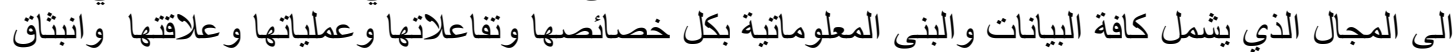

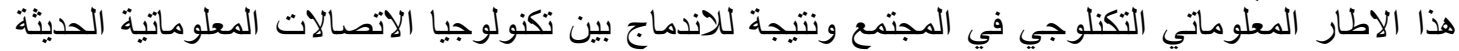

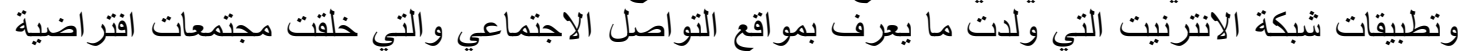

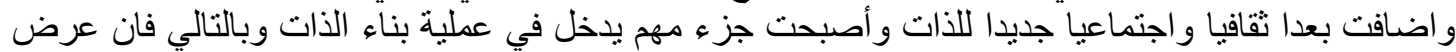

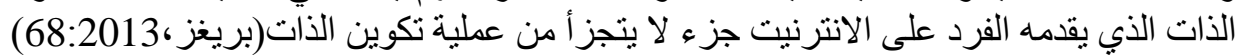

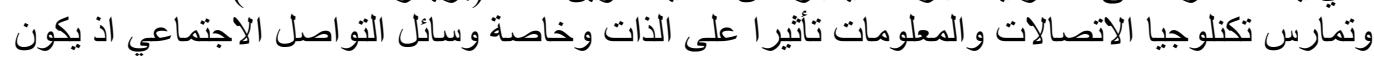

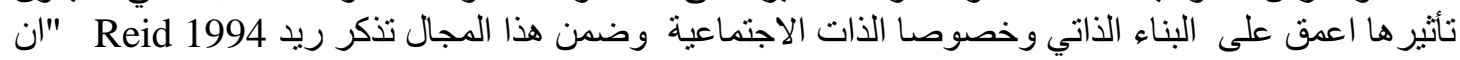

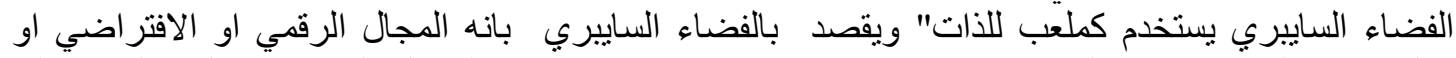

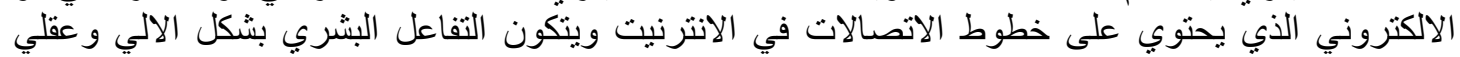

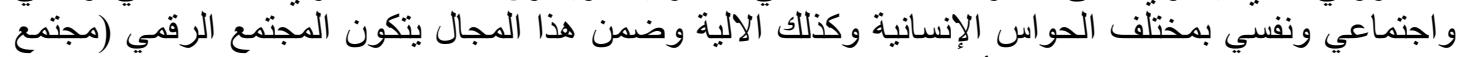

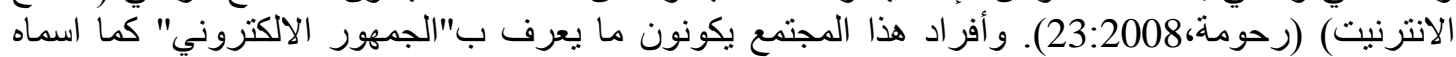

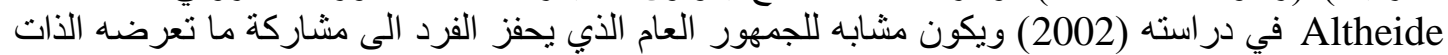

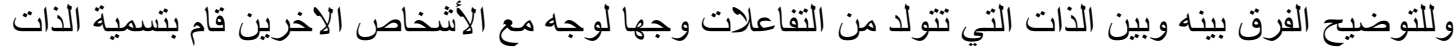

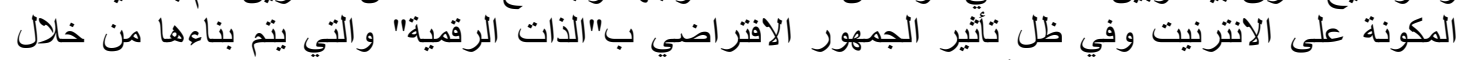

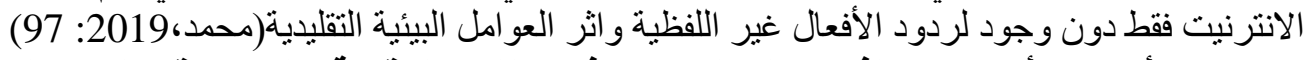

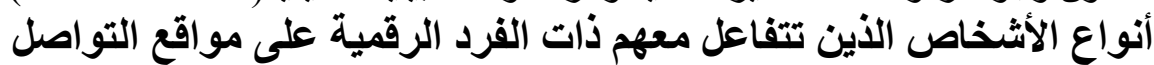

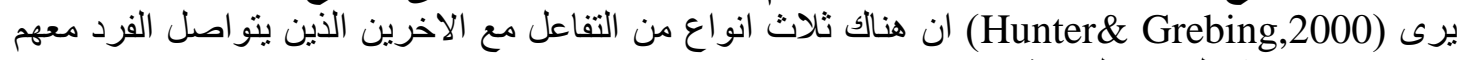
ويساهمون في تشكيل ذاته الرقمية

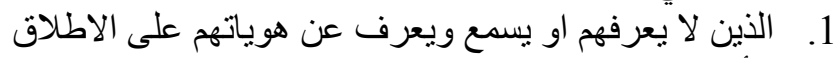
2.

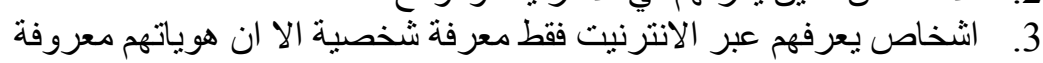
خصائص الأتات الرقمية

1- اختيارية: يختار ها الثخص ويسميها بمحض ار ادته بخلاف الذات المتكونة في العالم الو اقعي التي لا خيار

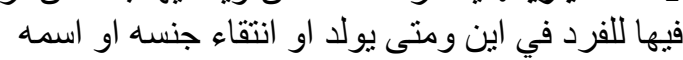

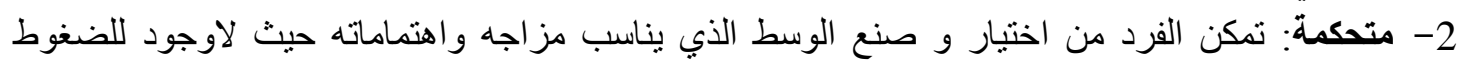

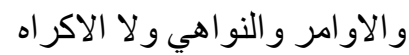

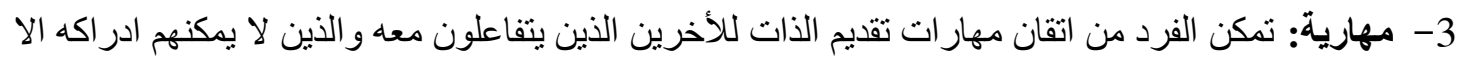

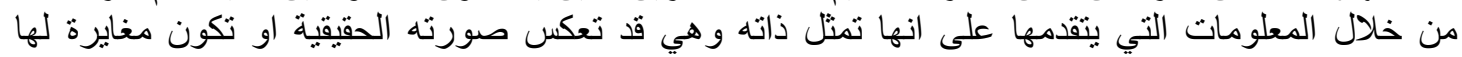

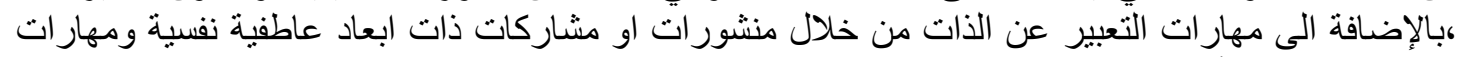

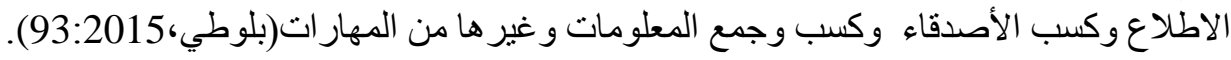

4- ن نظريات فسرت الذات الرقمية:

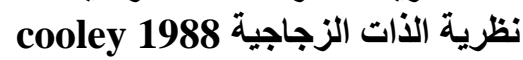
يعد كولي من رواد النية النظرية التفاعلية الرمزية التي ركزت التئ هذه النظرية على مبدأين أساسيين هما الرموز

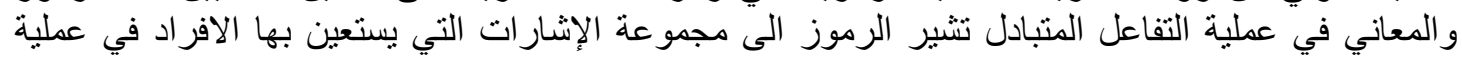




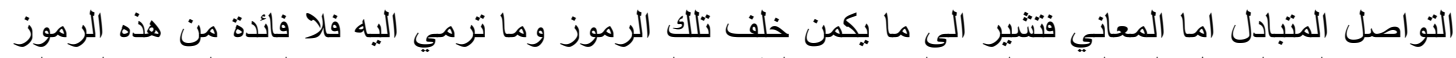

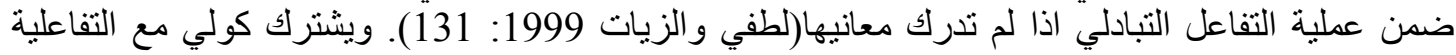

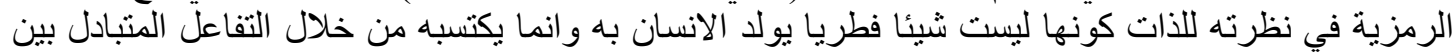

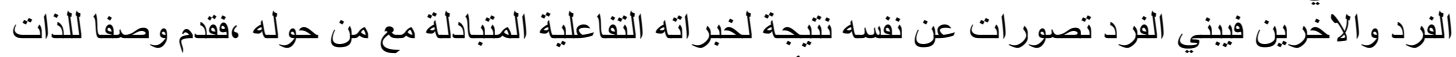

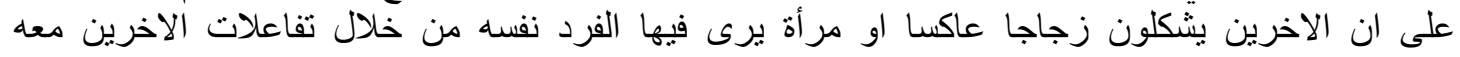
(Hensly,1992:4)

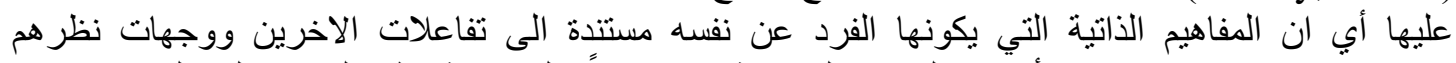

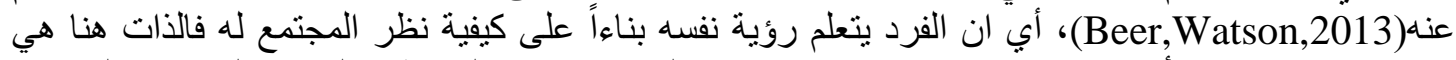

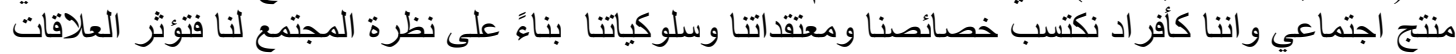

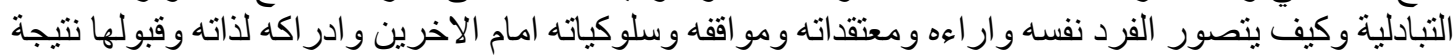

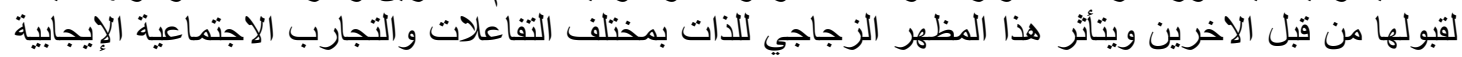

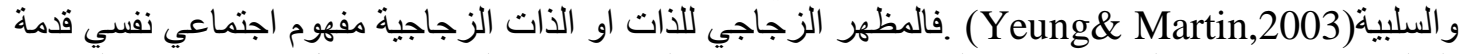

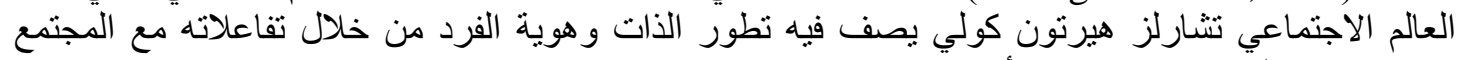
وتتضمن هذه الذات ثلاث مكونات أساسينة :

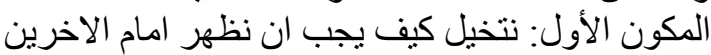

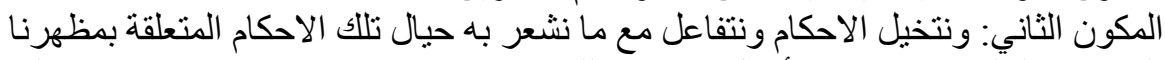

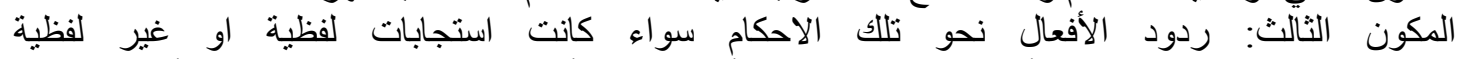

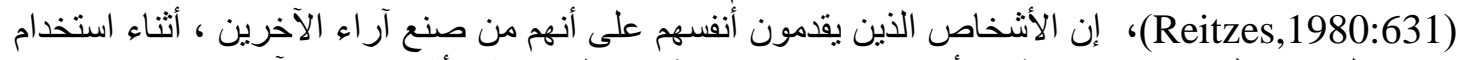

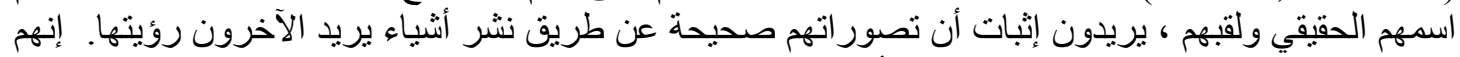

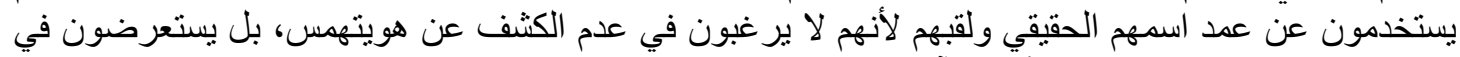

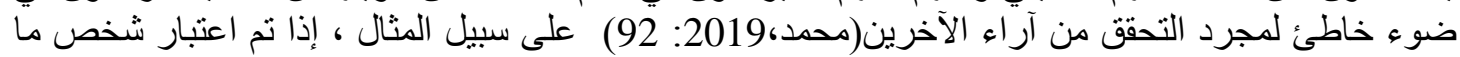

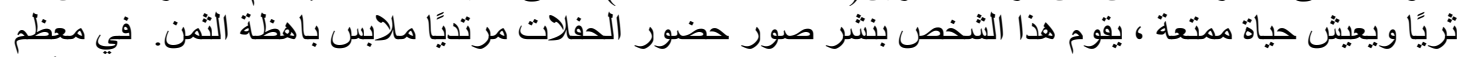

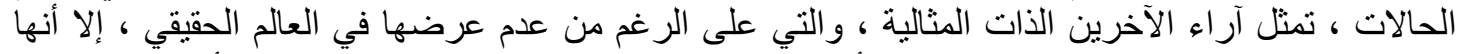

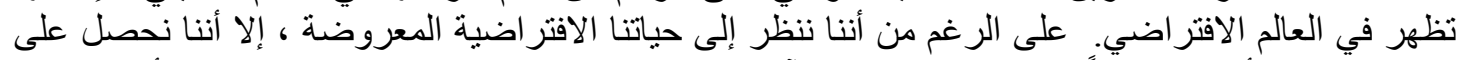

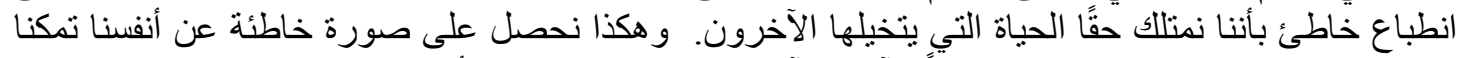

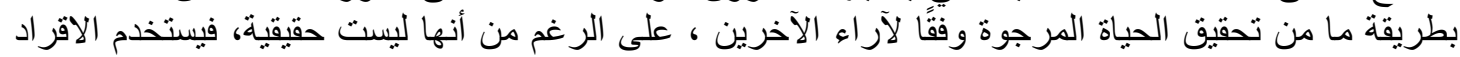

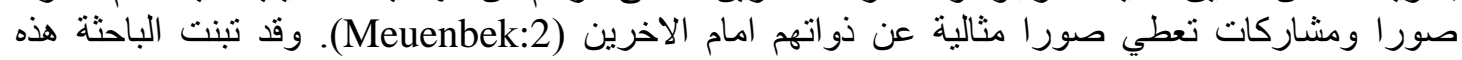
النظرية كونها 1- - من اول النظريات الني تناولت الذات الرقمية بشكل واضح فقد تناولته من جوانب مختلفة كالجوانب الثخصية والاجنماعية واتلفينية 2- كما تناولت الدراسات الأجنية نظرية الذات الزجاجية في تفسير الذات الرقمية.

$$
\text { المحور الثاني: دراسات سابقة }
$$

(Zhao,2005) سم الباحث و السنة البنة

\begin{tabular}{|c|c|}
\hline $\begin{array}{l}\text { الذات الرقمية:التفاعل مع الاخرين من خلال النظرة الزجاجية } \\
\text { THE DIGITAL SELF: THROUGH THE LOOKING GLASS OF } \\
\text { TELECOPRESENTOTHERS TEMPLE UNIVERSITY }\end{array}$ & عنوان البحث \\
\hline وريدا إكه لذاتحث الى معرفة تأثير الأنترنيت على تكوين الذات وتأثير الغرباء على نظرة الفرد & اهداف البحث \\
\hline للأخرين على مواقع التواصل تأثير على نظرة الفرد لذاته ولهم تأثيثر حيث فيثعلون الفرد نفسجاج & النتائج \\
\hline
\end{tabular}

محمد)(2019) اسم الباحث والسنة 


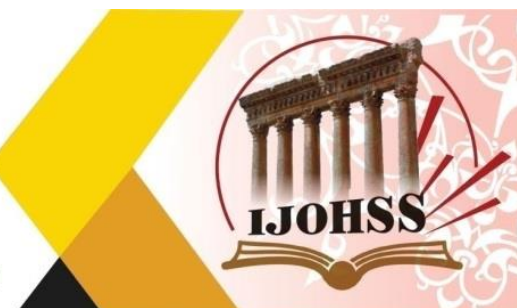

ISSN: 2415 - 4822

البنية العاملية للاتات الرقمية لاى المراهقين مستخدمي مواقع التواصل الاجتماعي

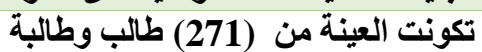

يهاف البحث الى تحديد ابعاد الذات الرقمية من خلال فحص البنية العاملية لمقياسها

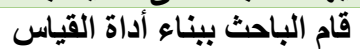

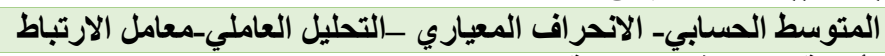
تحليد أربعة ابعاد للاتات الرقمية

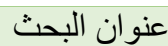
العينة

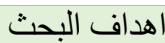

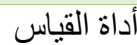

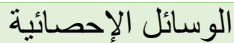
النتائج

\section{الفصل الثالث \\ منهجية البحث وإجراء(تهله}

استعملت الباحثة منهج البحث الوصفي حيث ان المنهج الوصفي يعد من أساليب البحث العلمي ، فأنه

أولا: منهجية البحث

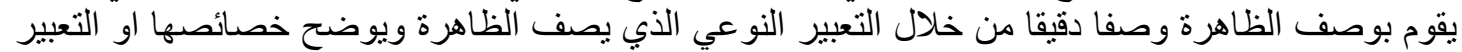

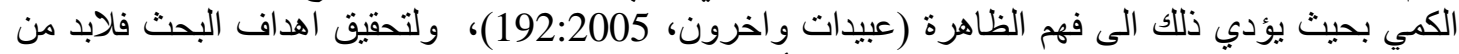

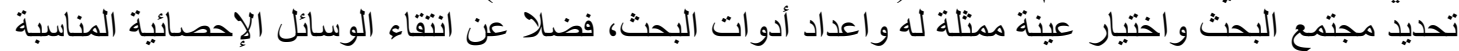

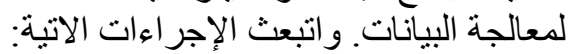

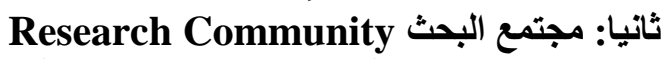
يقصد بمجتمع البحث جميع الافراد او العناصر التي تشترك في صفة واحدة او اكثر تميزه عن بقية

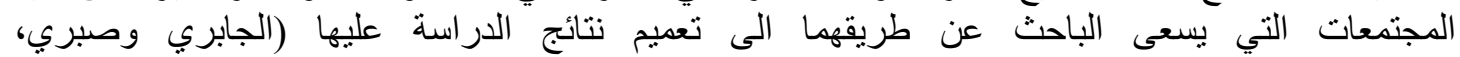

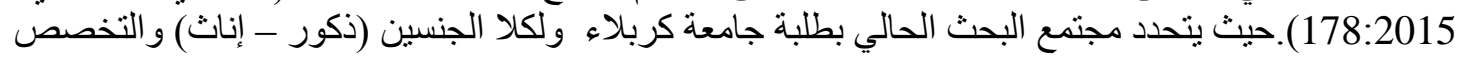

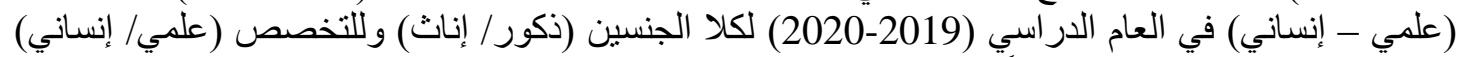

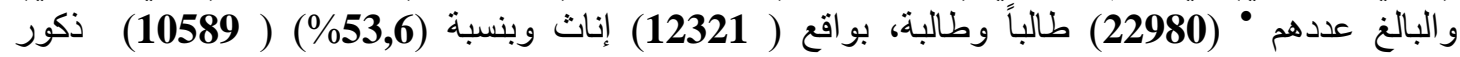

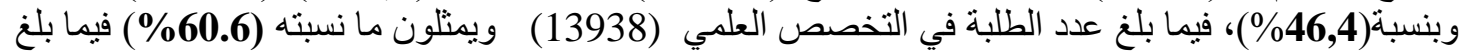

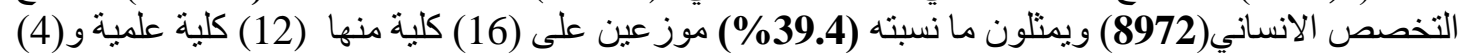

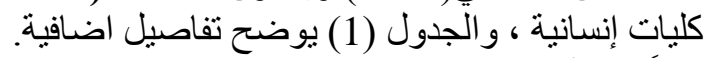
ثالثاً: عينة البحث

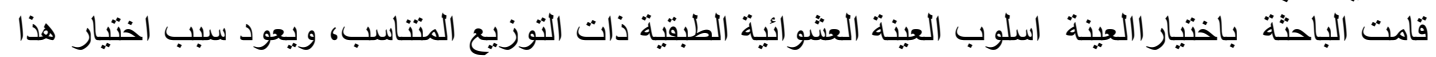

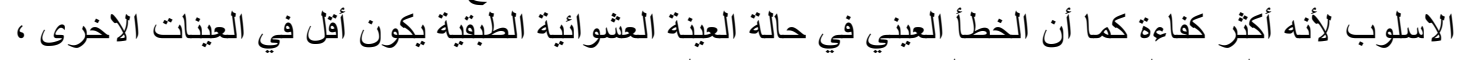

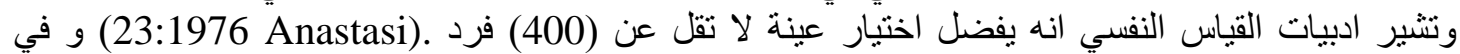

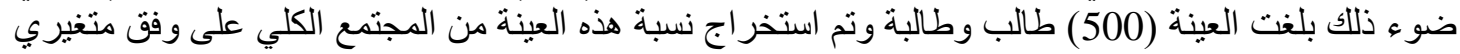

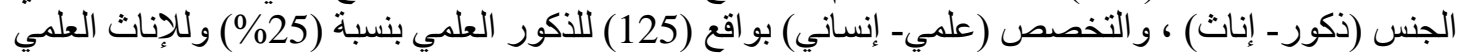
(125)وبنسبة (25\%) و الذكور الانساني بواقع (125) للذكور بنسبة (25\%) ولإنإناث (125) وبنسبة (25\%)

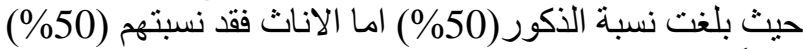

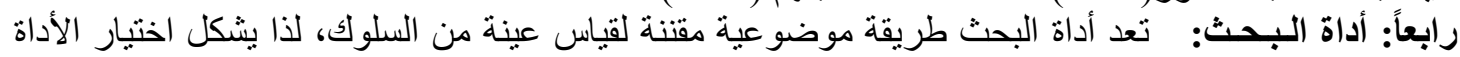

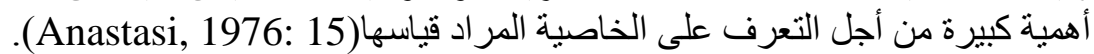

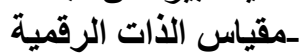

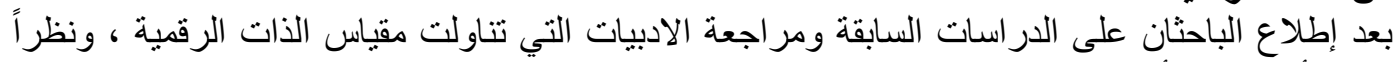

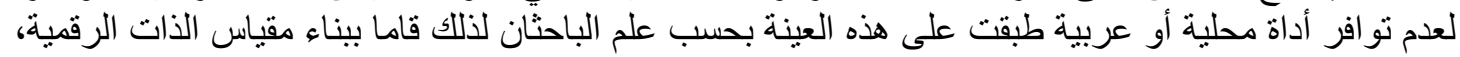

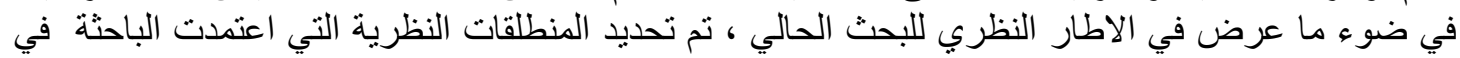
بناء المقياس لانها تعطي رؤية واضحة ينطلق منها البآحث للتحقق من إجر اءات بناء المقيد النياس و عليه حدد الباحثان 


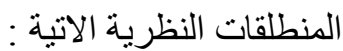

1- اعتماد نظرية الذات الزجاجية لتشارلز هيرتون كولي 1992 (Charles Horton Cooley)

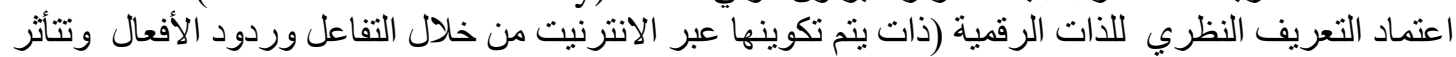

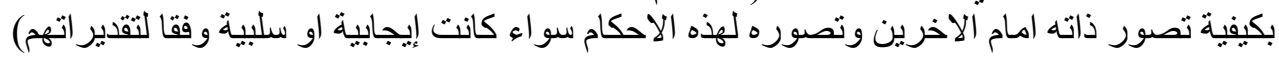

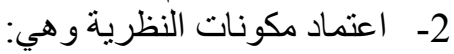

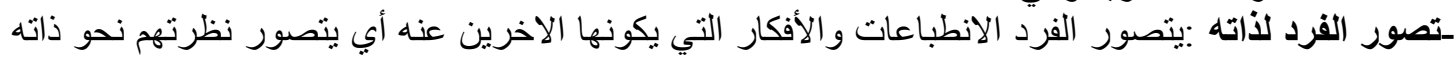

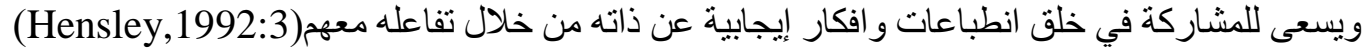

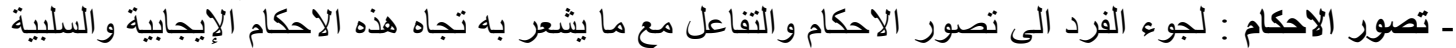

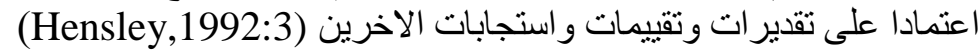

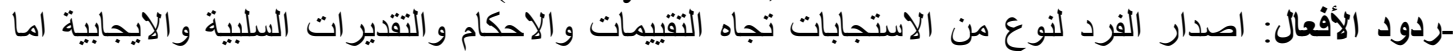

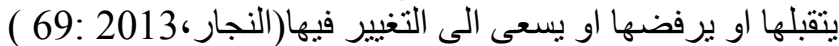

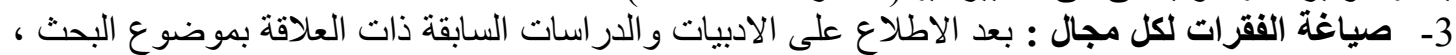

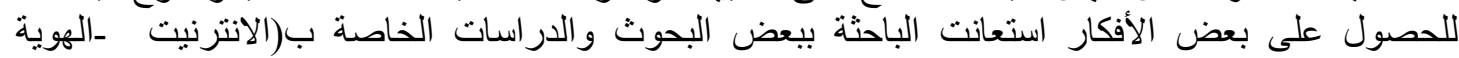

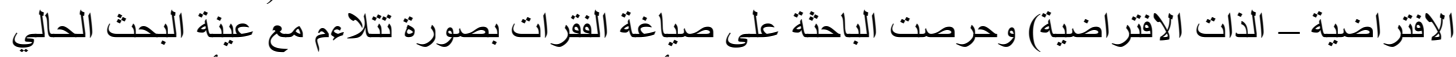

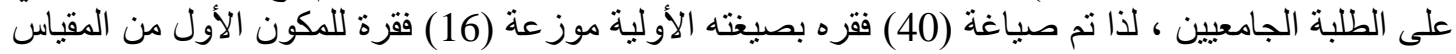

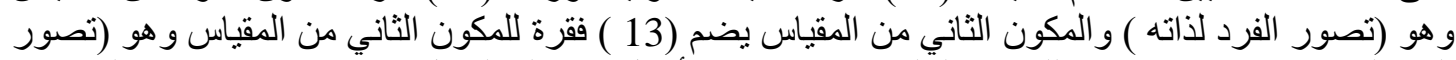

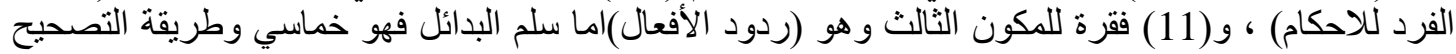

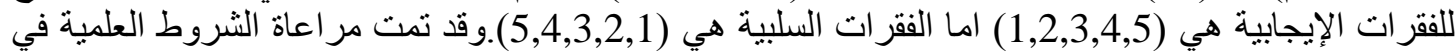

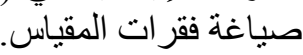

validity of scale items

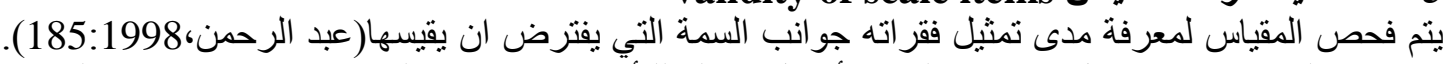

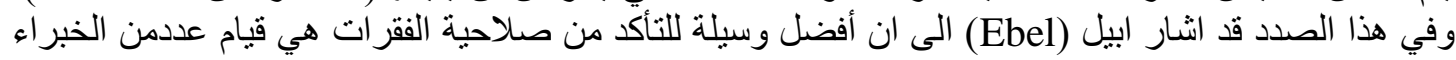
المختصين بتقرير صلاحيتها لقياس السمة (E) السمة

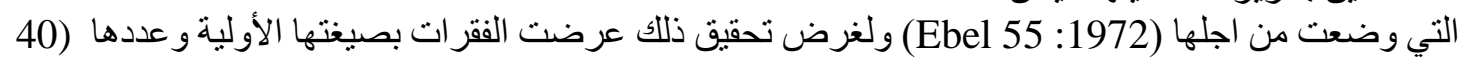

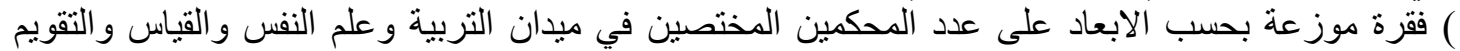

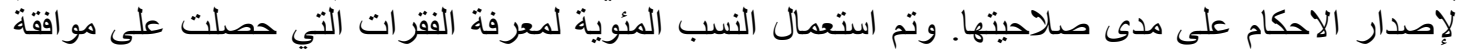

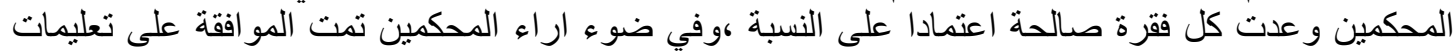

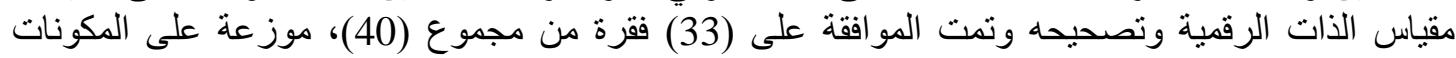
الثلاث و الجدول (1) يوضح ذلت ونهي 


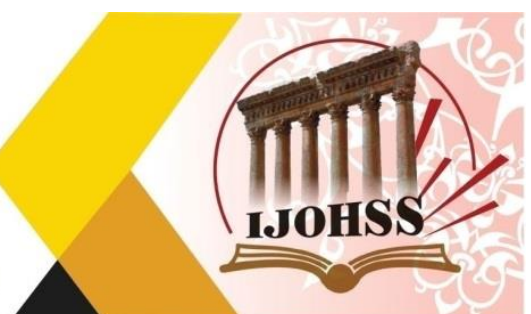

ISSN: $2415-4822$

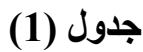

يوضع النسب المئوية لآراء الخبراء حول مقياس الذات الرقمية

\begin{tabular}{|c|c|c|c|c|}
\hline الالالة & عدد غير الموافقين & علد الموافقين & المئويةية & ارقام الفقرات \\
\hline دال & 0 & 24 & $100 \%$ & $\begin{array}{c}-4-5-7-14-15-19-20-21) \\
-22-23-25-28-31-32- \\
34-35-36-37 \\
(-38-39-30\end{array}$ \\
\hline ل دال & 2 & 22 & $\% 91.66$ & $(11-17-24-27)$ \\
\hline دال & 4 & 20 & 83.33 & $(2-3-18-26-38)$ \\
\hline غير دال & 15 & 9 & $\% 37.5$ & (6-10-12-13-16-29-40) \\
\hline
\end{tabular}

إعداد بدائل الإجابة وتصحيح المقياس:

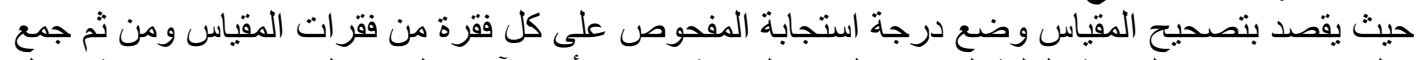

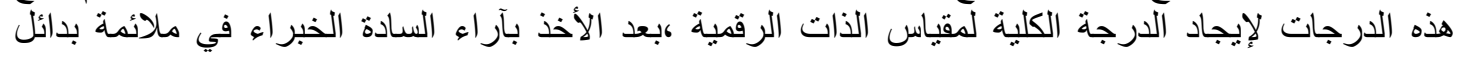

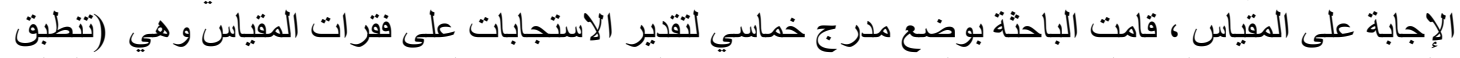

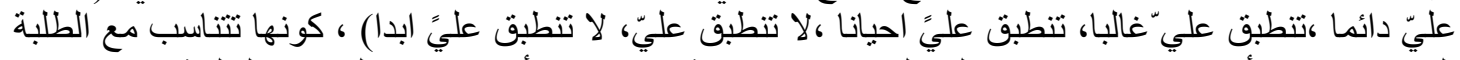

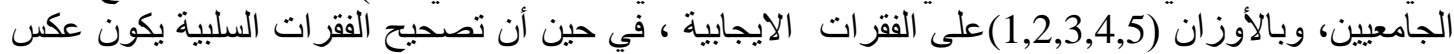

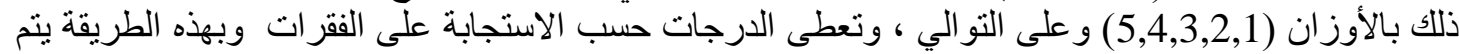

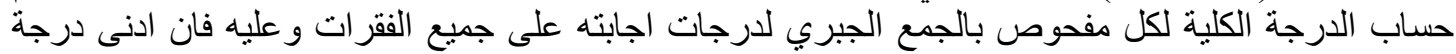

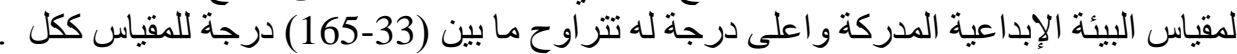

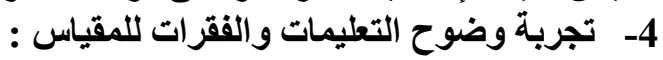

Experience the clarity of instructions and paragraphs of the scale: قام الباحثان بتطبيق مقياس الذات الرقية ملحق ( 4) على عينة اختيرت بطريقة عشو ائية من طلبة الجامعة

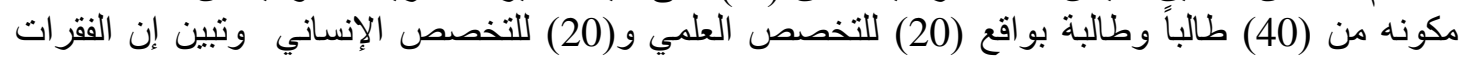

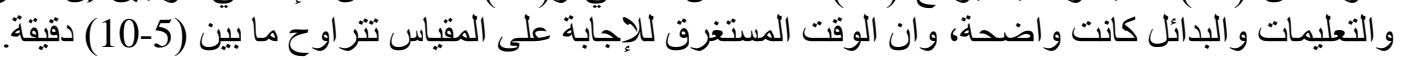

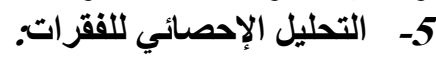

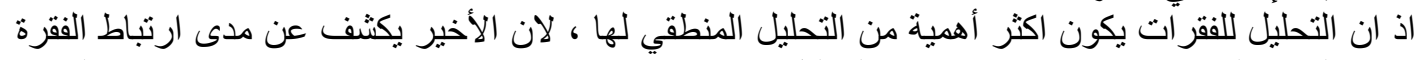

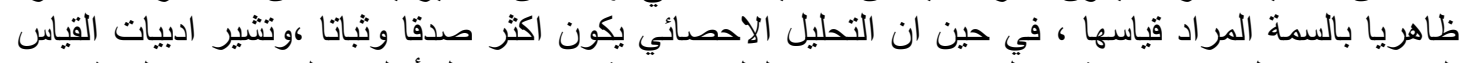

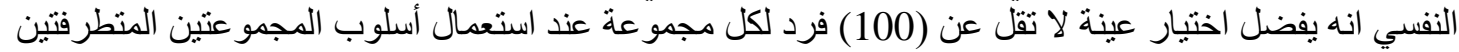

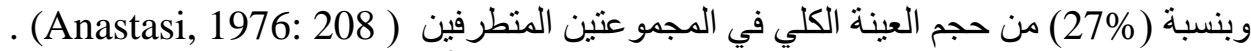

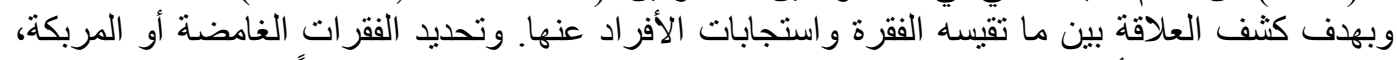

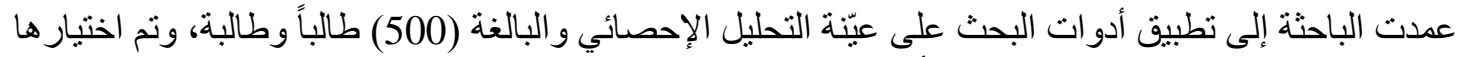

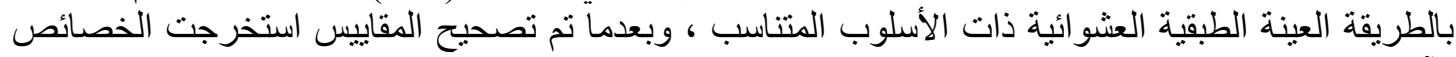
الآتية:

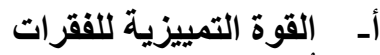

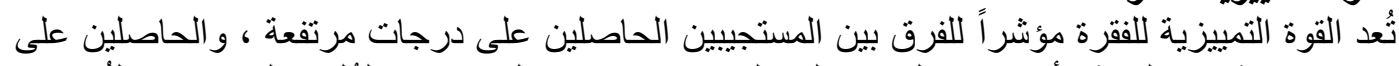

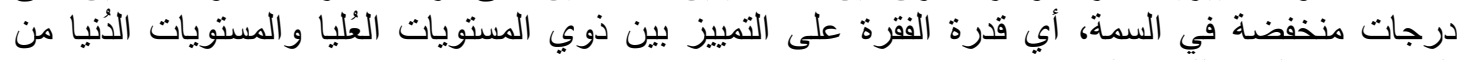

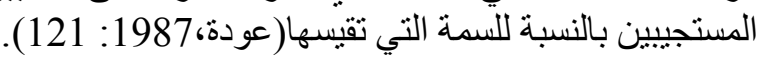
_القوة التمييزية بأسلوب المجموعتين المتطرفتين External consistency و لإجر اء ذللك اتبع الباحثنان ما يأني: 
ـ ـ تحديد الدرجة الكلية لكل استمارة من استمار ات مقياس الذات الرقمية التي طبقت على عينة تحليل الفقرات.

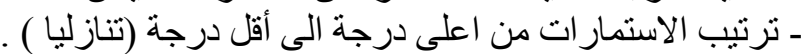

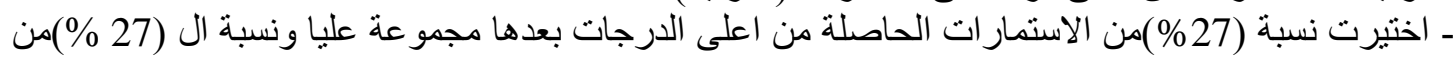

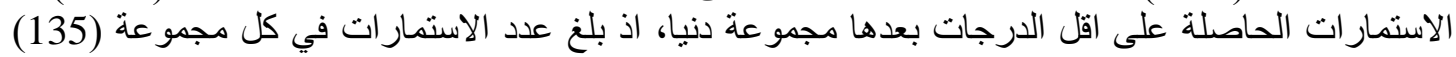

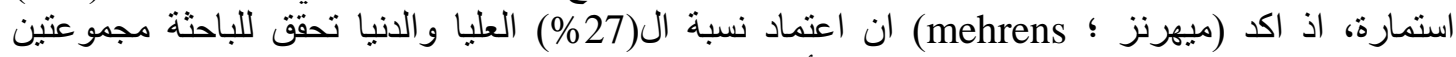

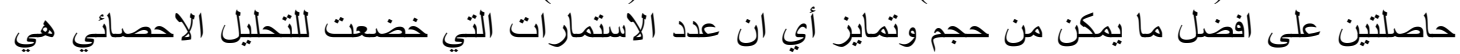
(270) (27) استمارة.

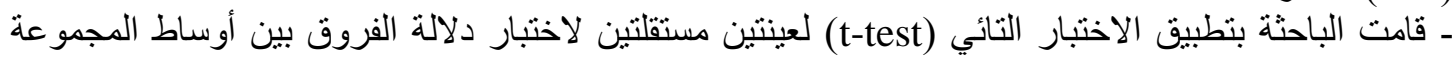

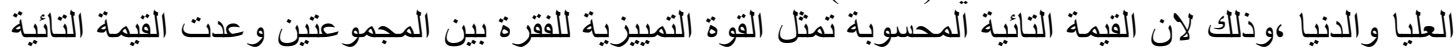

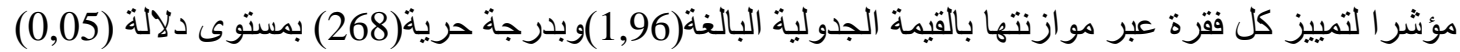

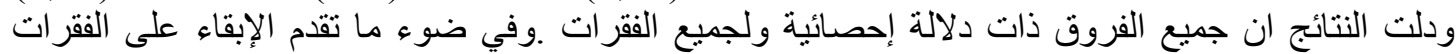

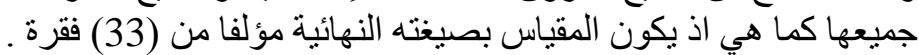

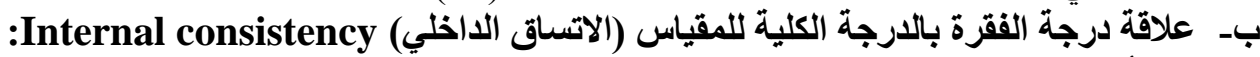

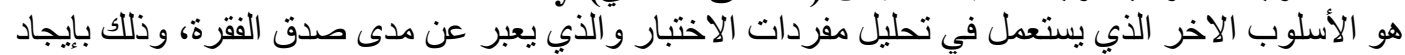

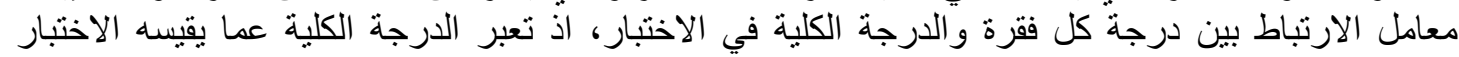

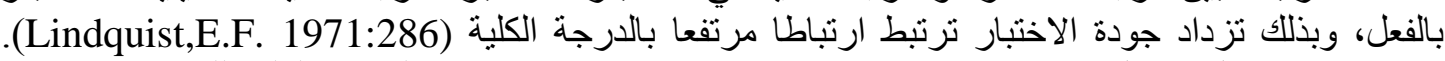

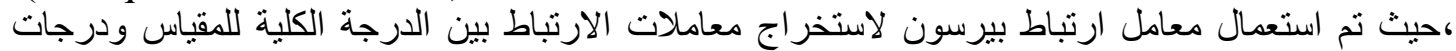

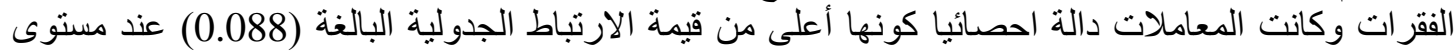

ت- علاقة درجة الفقرة بالمجال الأي ينتمي لمقياس الذات الرقات الرقية:

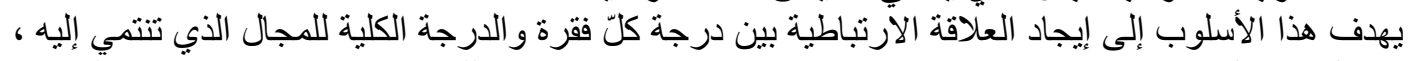

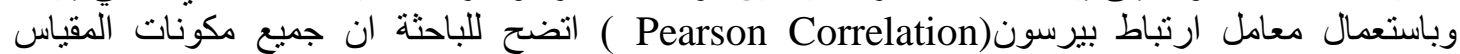

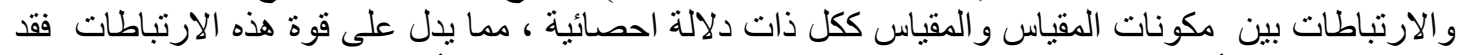

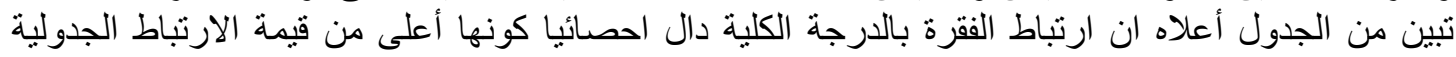

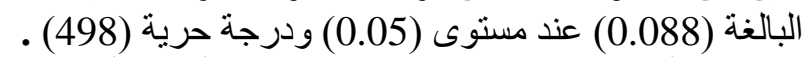

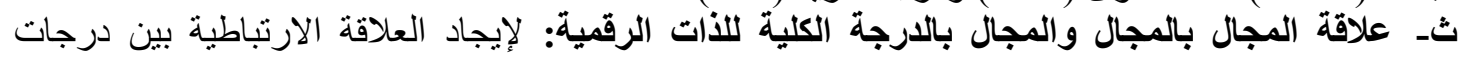

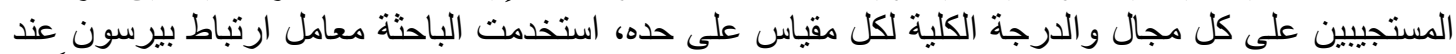

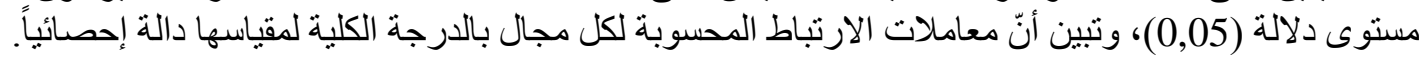

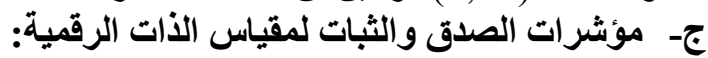

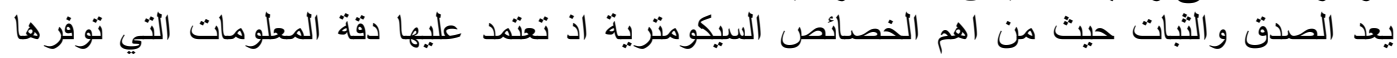

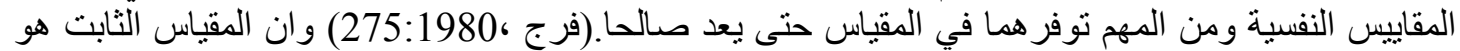

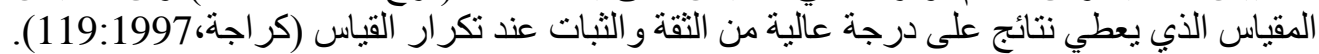

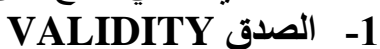
اذ استعمل الباحثان مؤشرين لصدق مقياس الذات الرقمية

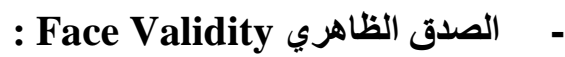

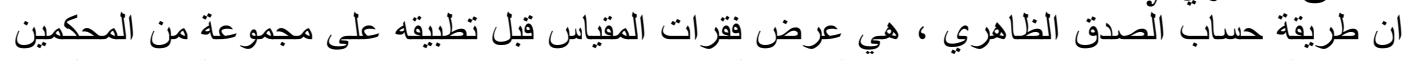

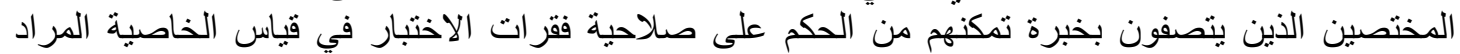

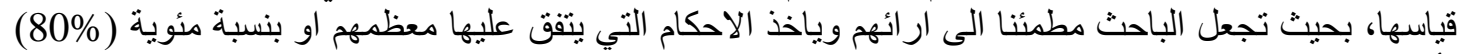

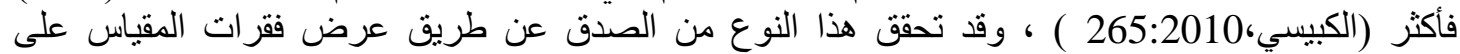

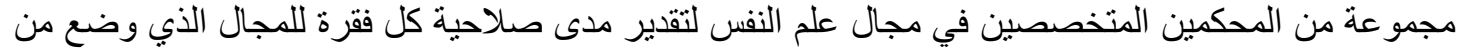




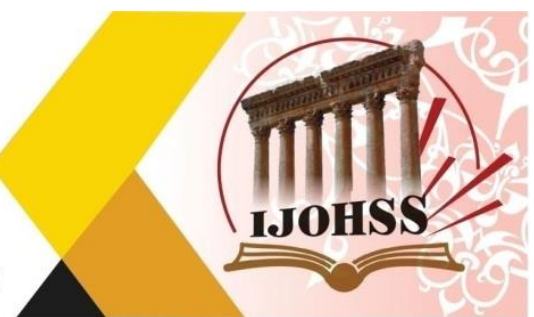

: Construct Validity -

أي تحليل درجات المقياس استنادا الى البناء النفسي للخاصية المر اد قياسها او المدى الذي يمنأك ان تقرر بموجبه

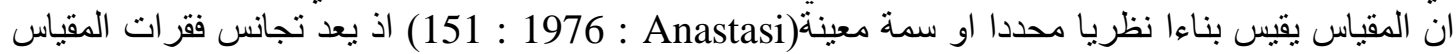

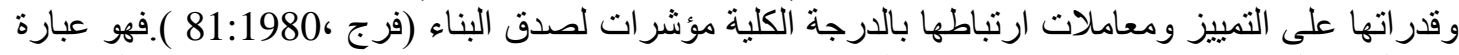

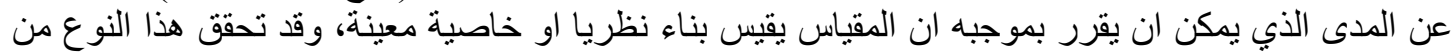
الصدق عن طريق المؤشر ات الاتية:

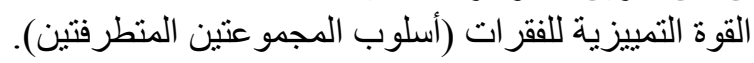

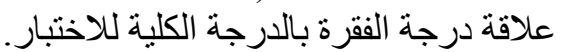
علاقة درجة الفقرة بالدرجة الكلية للمجال الذبي تلتنمي اليها.

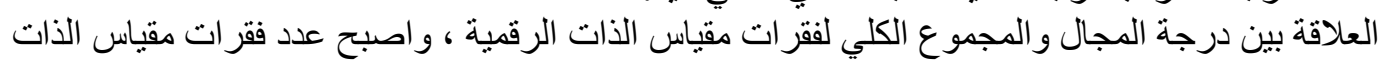
الرقمية بصيغته النهائية (33) فقرة النئ.

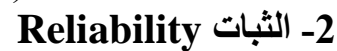

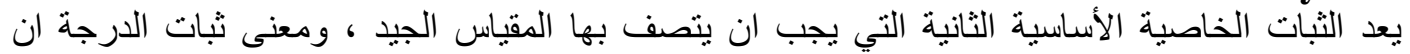

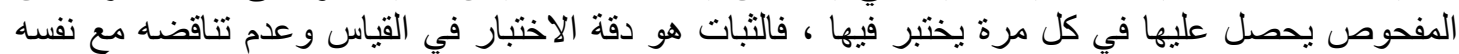

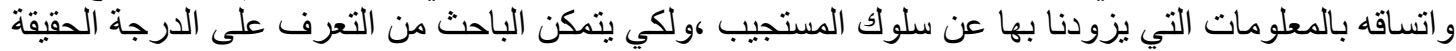

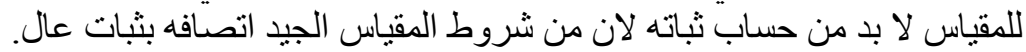

(103: 1976 .Anastasi)

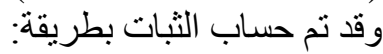

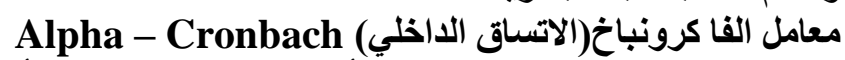

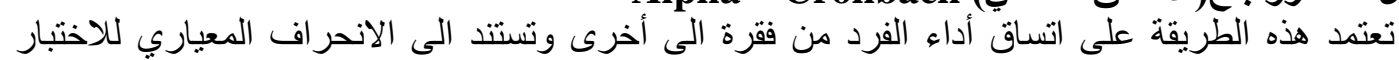

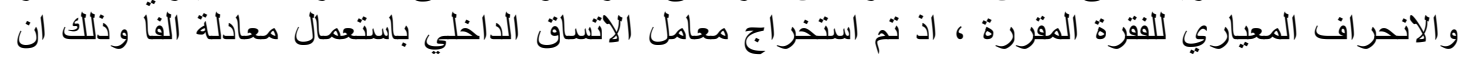

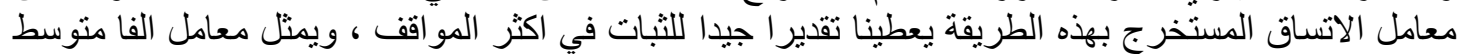

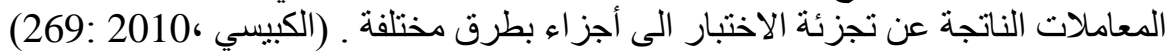

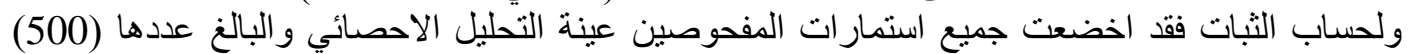

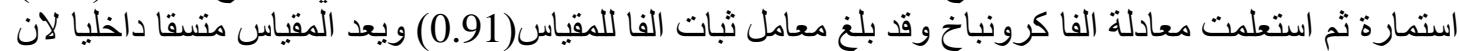

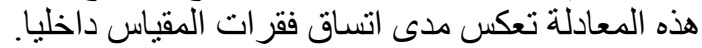

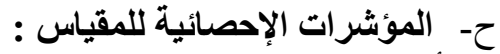

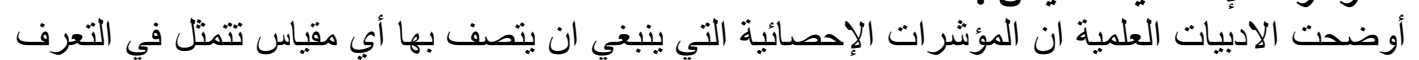

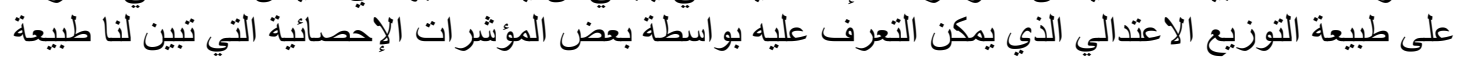

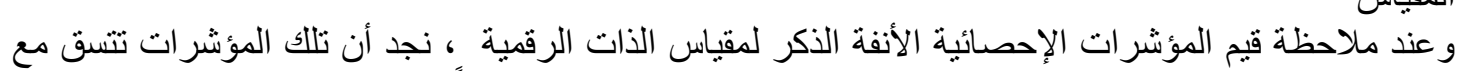

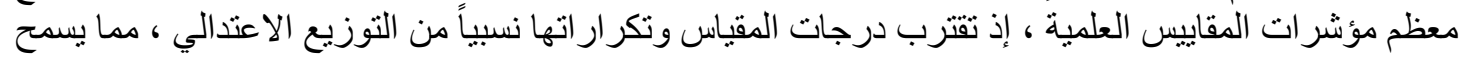

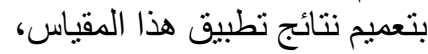

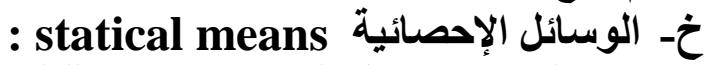

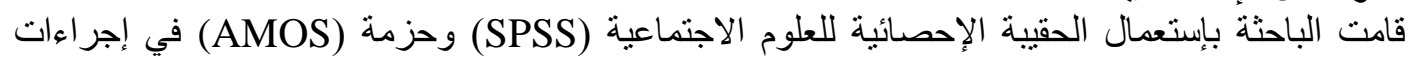

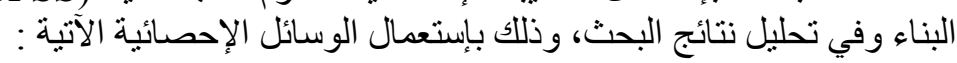

1- الاختبار التائي لعينتين مستقلتين T-test Two Independent Samples لاستخر اج القوة التمييزية (بأسلوب المجمو عتينين الطرفينتين) لفقرات المقين المقياسين.

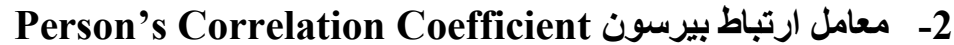

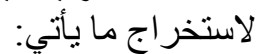
أـ القوة التمييزية (بأسلوب علاقة درجة كل فقرة بالمجموع الكلي لدرجات المقياس) لفقرات المقياسين. 


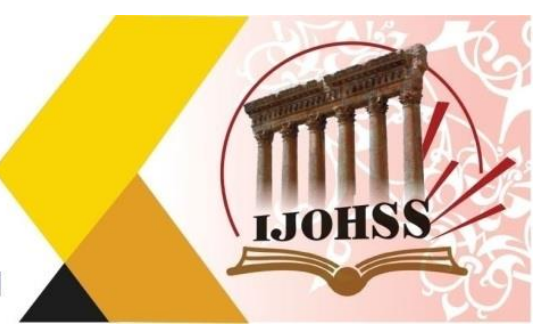

$$
\begin{aligned}
& \text { بـ لغرض استخر اج العلاقة بين درجة كل مجال من مجالات المقياس و الدرجة الكلية للمقياس. }
\end{aligned}
$$

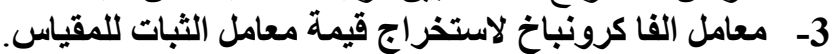

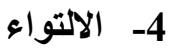

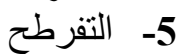

$$
\begin{aligned}
& \text { 6- الاختبار التائي لعينة واحدة T test for one Sample }
\end{aligned}
$$

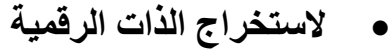

$$
\begin{aligned}
& \text { 7- تحليل التباين الثنائي استخدم لاستخراج الفروق لكل من (الجنس، التخصص). }
\end{aligned}
$$

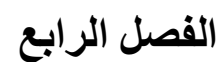

$$
\begin{aligned}
& \text { عرض النتائج ومناقشته الرعا }
\end{aligned}
$$

فيما يلي عرضا لنتائج البحث التي تم التوصل إليها في ضوء أهدافه، وسيتم عرضها على وفق تسلسل أهداف

$$
\text { 1- الهـف الاول: التعرف على الأت الرقمية لاى عينة البحث. }
$$

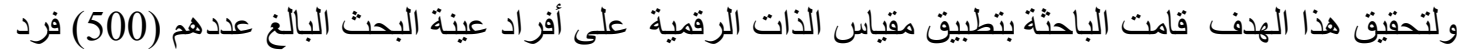

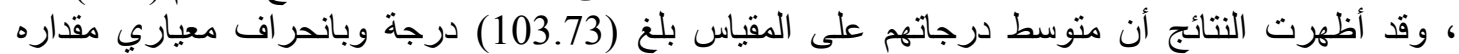

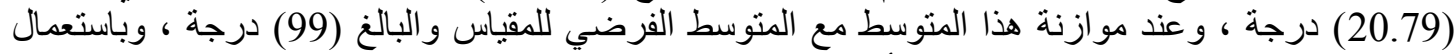

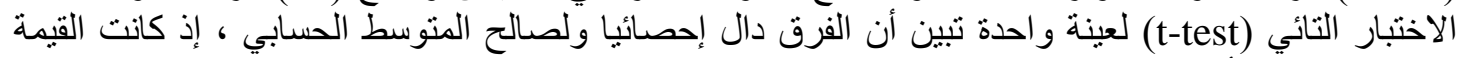

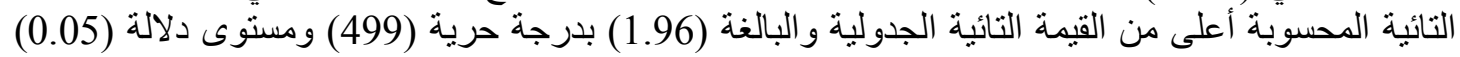

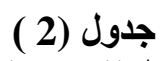

\begin{tabular}{|c|c|c|c|c|c|c|c|}
\hline مستوى الدلالة & الحرية & التائية & القيمسة التائية & الفرضيط & الالانحراف & الحستوسي & العبنة \\
\hline دال & 499 & 1.96 & 5.09 & 99 & 20.79 & 103.73 & 500 \\
\hline
\end{tabular}

$$
\text { و الجدول (1) يوضح ذلك. }
$$

الاختبار التائي للفرق بين متوسط العينة والمتوسط الفرضي لمقياس الأات الرقمية

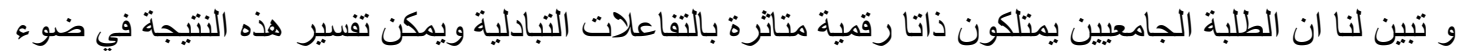

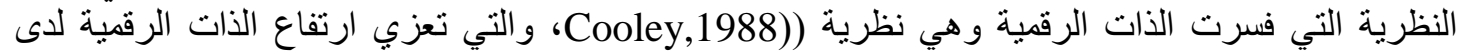

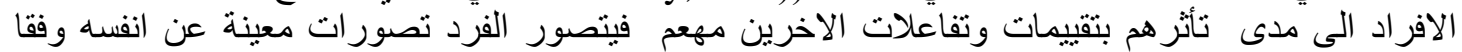

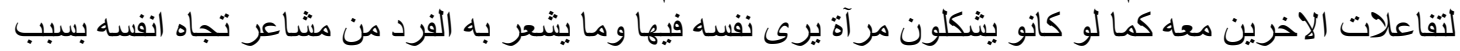

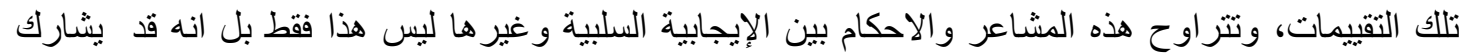

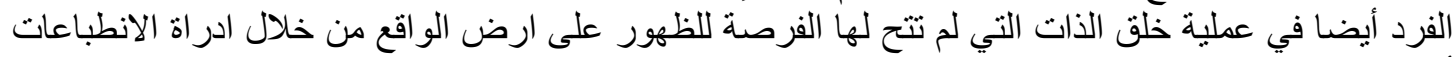

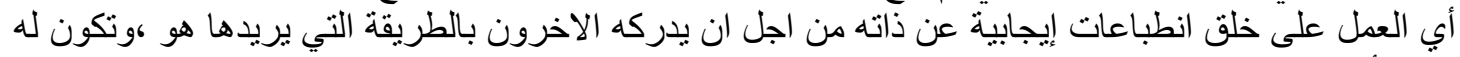

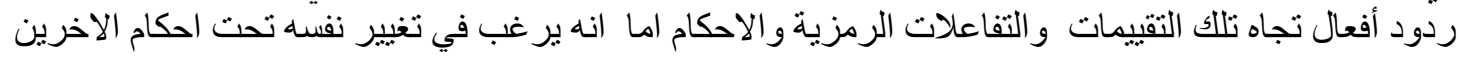

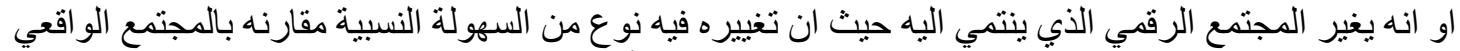

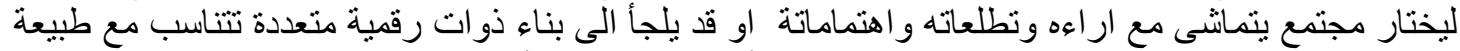

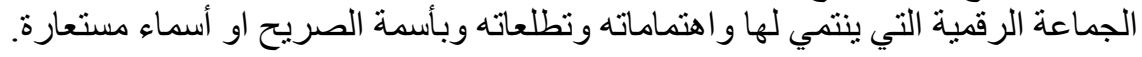




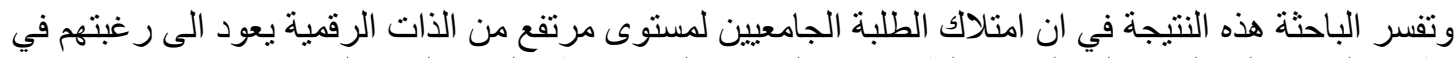

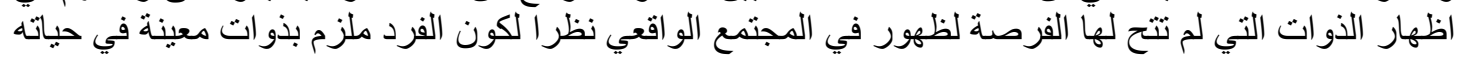

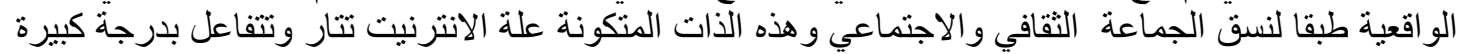

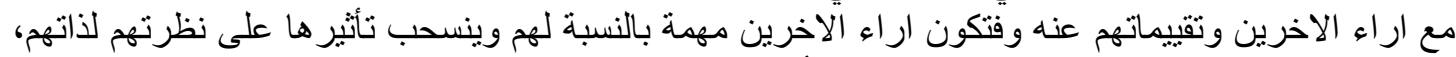

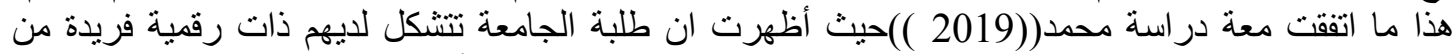

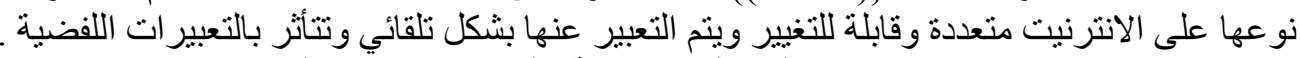

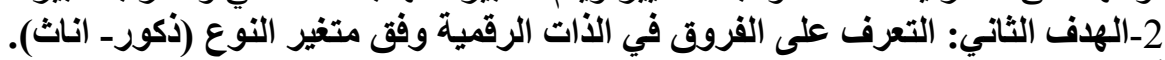

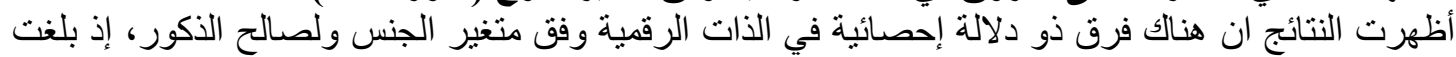

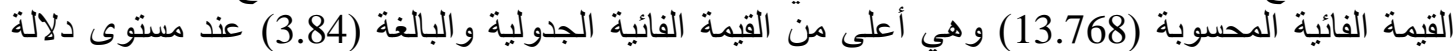

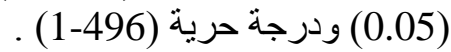

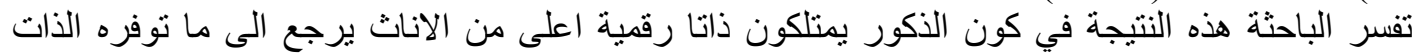

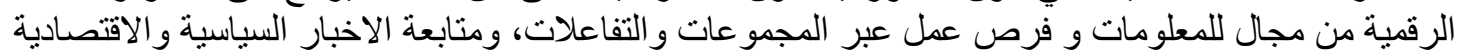

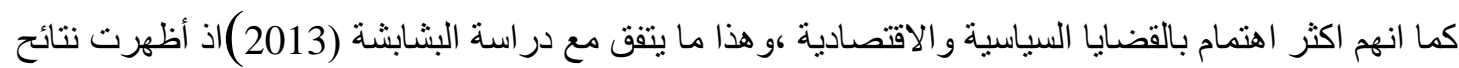

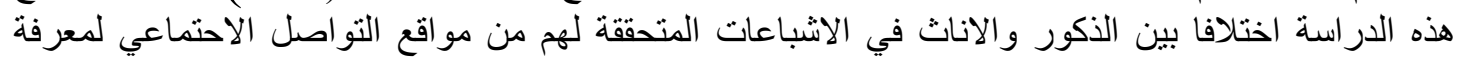

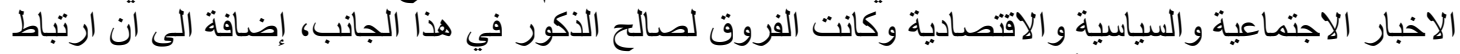

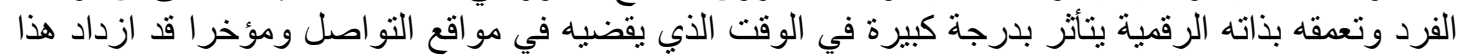

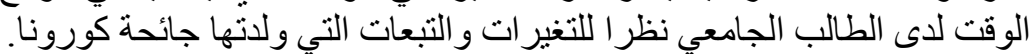

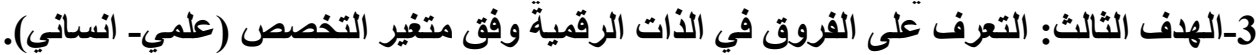

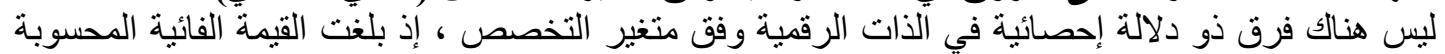

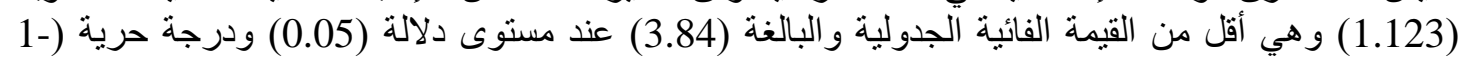

ومن النتيجة أعلاه اشارت الى عدم وجود فروق ذات دلالة احصائة في الذات الرقمية حسب متغير التخصص التصد

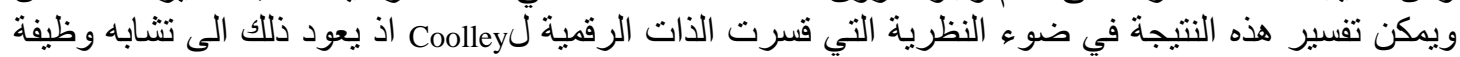

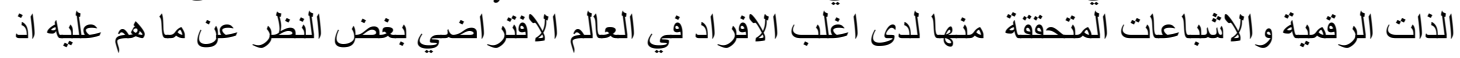

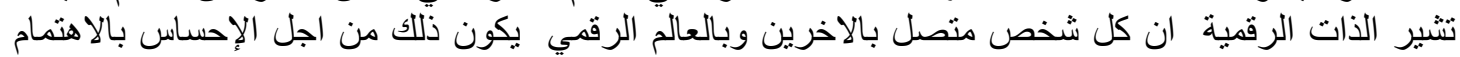

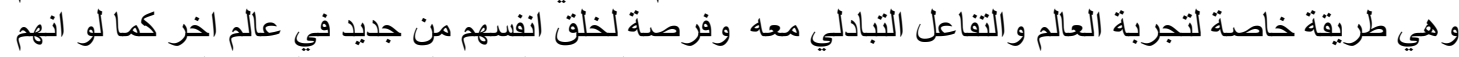

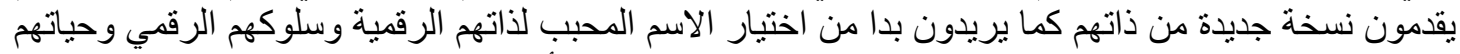

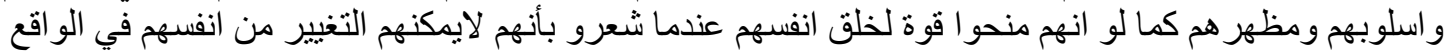

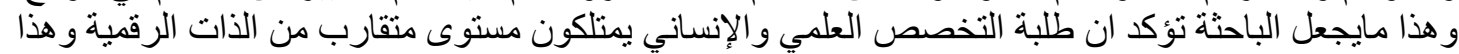

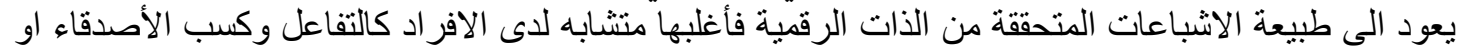

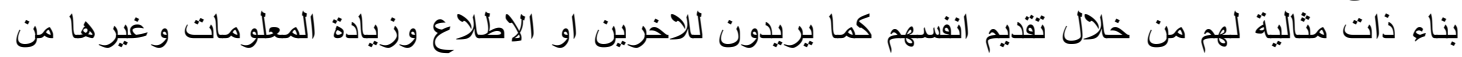

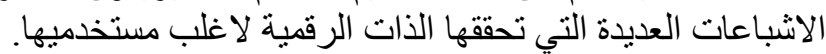

الاستنتاجات الات العاع

1- الطلبة الجامعيين بصورة عامة يمتلكون ذات رقمية مرتفعة ومتأثرة بالتفاعلات المجتمع الرقمي اذ لديهم

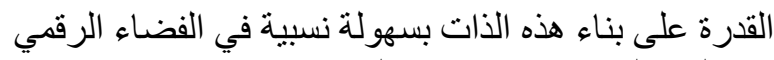
3- - لدى الذكور ذاتا رقمية اعلى من الاناث.

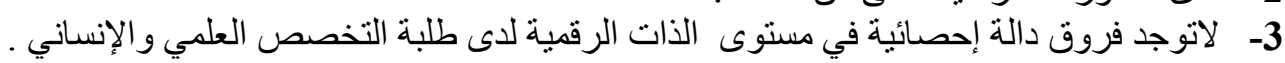
التوصيات

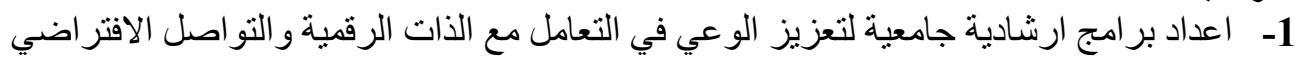

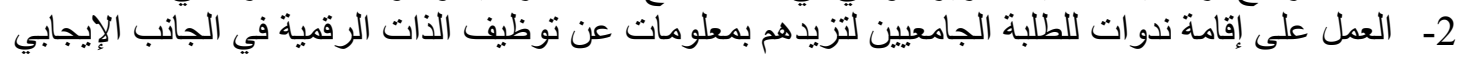
التطويري للذات. 
اجر اء در اسة لبحوث مستقبلية :

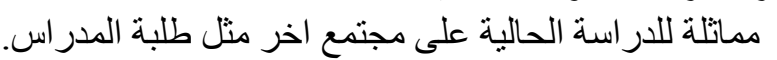
العلاقة بين الذات الرقية وبعض المبن المتغير ات النفسية

1. الامام، مصطفى محمود و اوخرون(1990): القياس و والتقويم، جامعة بغداد.

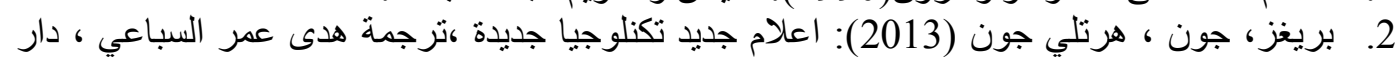

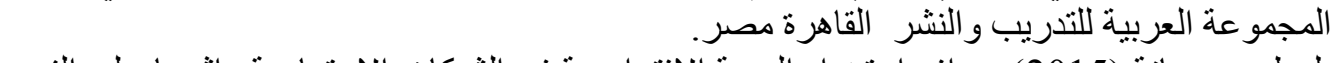

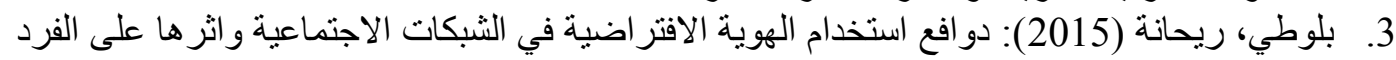

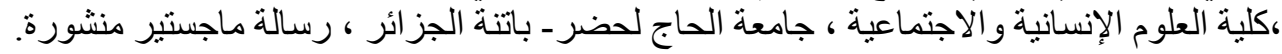

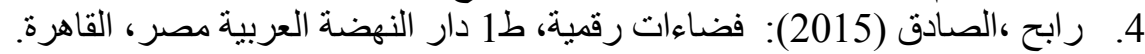

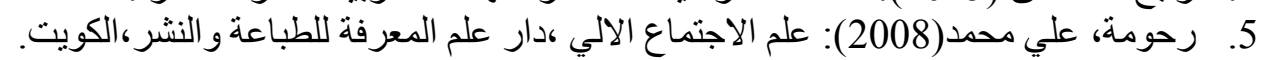

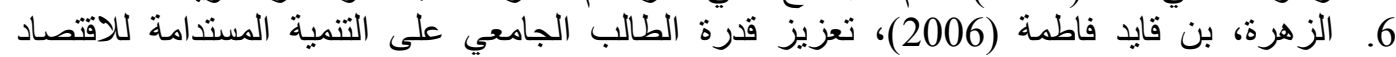

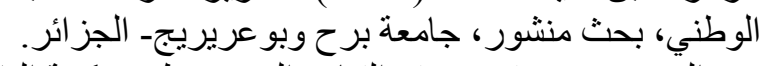
7.

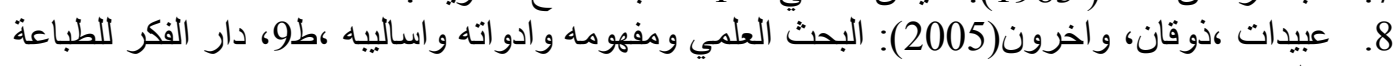

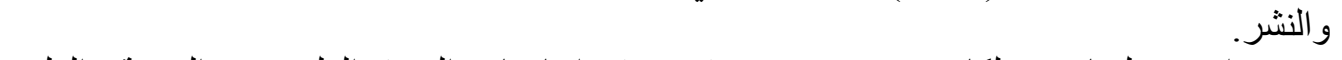

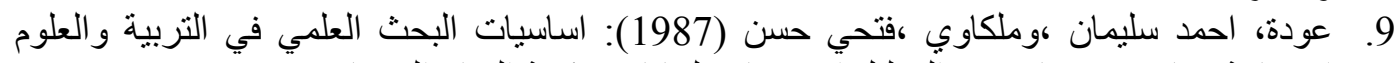

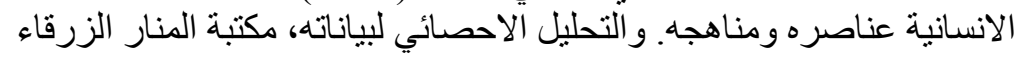

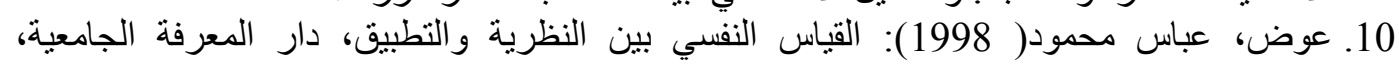

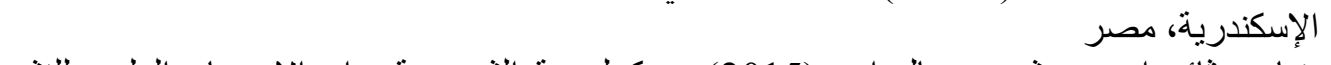

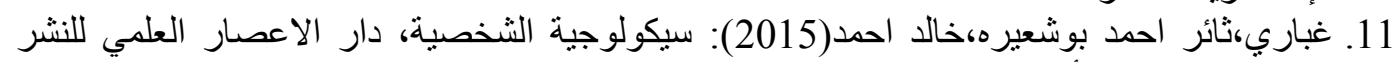
و التوزيع ، عمان ، الأردن.

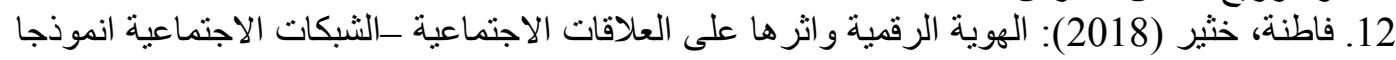

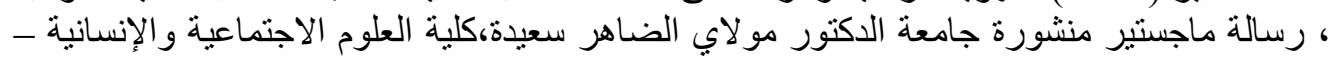

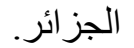
13. فرج، صفوت (1980): القياس النفسي، ط1، النهاء دار الفكر العربي، القاهرة.

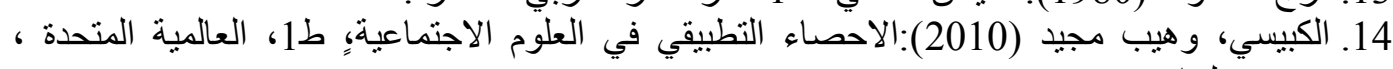
بيروت، لبنان. 15. كر اجة، عبد القادر(1997):القياس و التقويم في علم النفس،ط1،دار اليازوري العالمية للنشر و التوزيع ،

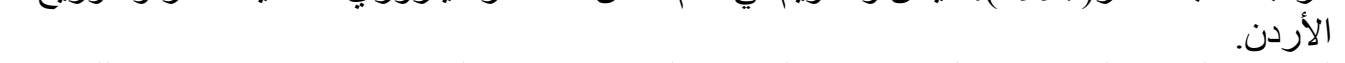
16. لطفي، طلعت والزيات، كمال(1997): النظرية المعاصرة في علم الاجتماع ، دار غريب للطباعة

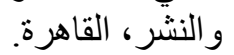
17. محمد، امل محمد جمعة (2019): البنية العاملية للأات الرقمية لاى المراهية اهقين مستخدمي مواقع

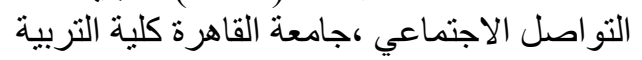

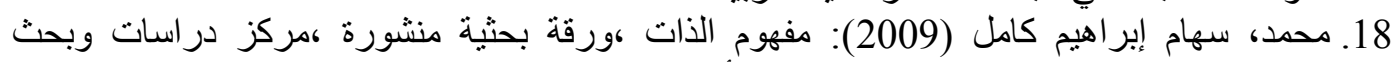

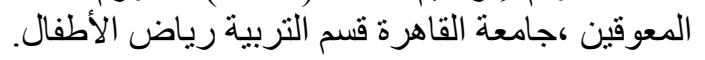

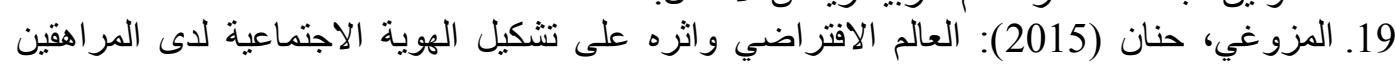

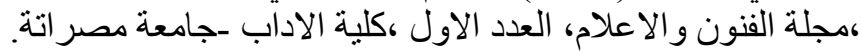

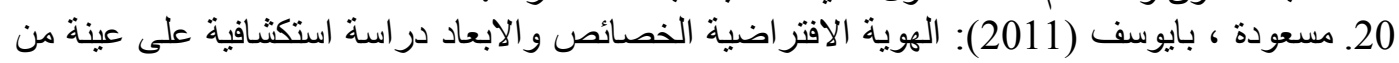

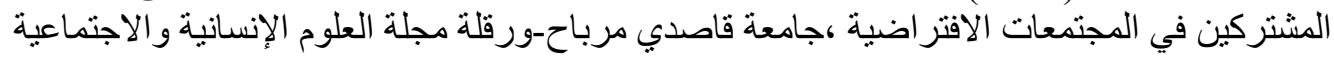




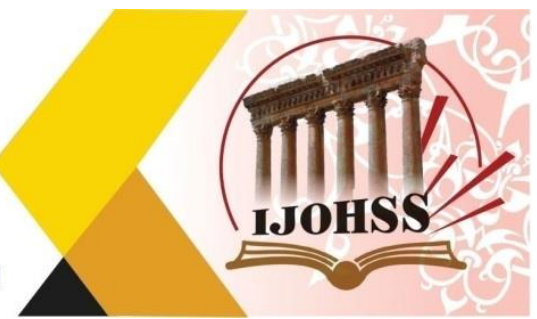

21. النجار، صباح احمد محمد ،(2013): العلاقات السوسيومنيرية في الجماعات الصغيرة، ط1 ،دار

$$
\text { الحامد للنشر و التوزيع عمان: الأردن. }
$$

22. اليعقوبي،حيدر حسن (2013): التقويم والقئرنياس في العلوم التربوية و النفسية رؤية تطبيقية ،دار الكفيل

$$
\text { للنشر والتوزيع. }
$$

23. Altheide, David 1. (2002).Identity And The Definition Of The Situation In a Mass-Mediated Context, Symbolic Interaction, 23 (1): 1-27.

24. Anastasi A , \& urbinas .(1979). psychologicall Testing, New York Macmillan.

25. Beer, A.,Watson, D. ,\& McDade-Montez, E. (2013). Self-other agreement and assumed similarity in neuroticism, extraversion, and trait affect : Distinguishing the effects of from and content assessment , 20 (6).

26. Belk, Russell W.(1988). Possessions And The Extended Self ,Journal Of Consumer Research .Vol. 15.

27. Ebel, R.L . (1972). Essentials of Education Measurement, New Jersy, Englewood cliffs prentice-Hall.

28. Hensley, Wayne E.(1992). The Theoretical Intersection of the looking-glassself , state University, Competitively selected paper presented at the annual speech communication association convention; Chicago, October -29, 1992

29. J.scheff ,Thomas (2005). Looking glass self Goffman as symbolic Interactionist University of California, symbolic Interactionist vol.28, lssue 2.

30. Mark, Barrenchea. (2017). The Digital Self Retrieved, September, 12,2019, From: HTTPS://BIOGS.OPENTEXT.COM/THE-DIGITAL-SELF

31. Reitzes D. (1980). Beyond the Looking Glass Self:Cooley Social self and its treatment in Introductory .

32. Zhao, shanyang.(2005). The digital self: through the looking glass Of Telecopresent Others. temple universit 